\title{
WORKING
}

paper

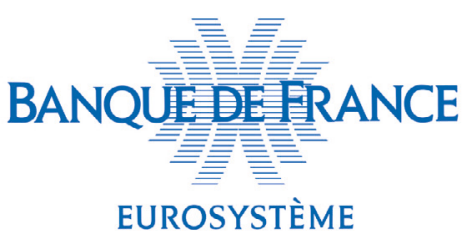

EUROSYSTÈME

\section{A General Equilibrium Appraisal of Capital Shortfall}

\section{Eric Jondeau ${ }^{1} \&$ Jean-Guillaume Sahuc ${ }^{2}$}

\author{
March 2018, WP \#668
}

\begin{abstract}
We quantify the capital shortfall that results from a global financial crisis by using a macrofinance dynamic stochastic general equilibrium model that captures the interactions between the financial and real sectors of the economy. We show that a crisis similar to that observed in 2008 generates a capital shortfall (or stressed expected loss, SEL) equal to $2.8 \%$ of euro-area GDP, which corresponds to approximately 250 billion euros. We also find that using a cycle-dependent capital ratio that combines concern for both credit growth and SEL has a positive effect on output growth while mitigating the excessive risk taking of the banking system. Finally, our estimates confirm that most of the variability of the macroeconomic and financial variables at business cycle frequencies is due to investment and risk shocks.
\end{abstract}

Keywords: capital shortfall, systemic risk, leverage, financial system, euro area, DSGE model. JEL classification: E32 ; E44 ; G01 ; G21.

\footnotetext{
${ }^{1}$ Swiss Finance Institute and Institute of Banking and Finance, Faculty of Business and Economics (HEC Lausanne), University of Lausanne, Extranef 232, CH-1015 Lausanne, Switzerland, eric.jondeau@unil.ch. ${ }^{2}$ Banque de France, 31 rue Croix des Petits Champs, 75049 Paris, France, jean-guillaume.sahuc@,banquefrance.fr.

We thank Gilbert Cette, Laurent Clerc, Michel Juillard, Julien Matheron, Benoît Mojon, and the participants of several conferences for their useful comments and suggestions.

Working Papers reflect the opinions of the authors and do not necessarily express the views of the Banque de France or the European Investment Bank. This document is available on publications.banque-france.fr/en
} 


\section{NON-TECHNICAL SUMMARY}

A fundamental difference in corporate funding between the euro area and the United States is that European firms rely more heavily on bank lending. Of all corporate debt in the euro area, 80\% comes from bank lending and 20\% from corporate bond markets, almost the inverse of the situation in the United States. In this context, when a global financial crisis occurs, the safeguard of the bank lending channel may lead to potentially high costs for European taxpayers. In a recent comprehensive assessment combining an asset quality review and a stress test on 130 euro-area banks, the European Central Bank (ECB) estimated that in a severely adverse scenario, the lack of capital would be close to 263 billion euros (ECB, 2014). This assessment, which is performed at individual bank level, requires a massive analysis of bank portfolios, including the valuation of loans and collateral items and the review of valuation models. It is therefore very time consuming and has been performed so far on a biannual basis only. It also suffers from two major drawbacks. First, it evaluates the impact of the scenario on individual bank balance sheets, assuming that banks do not react to the scenario (static balance sheet assumption). Second, and more importantly, it does not take the interaction between the banking system and the rest of the economy into account.

The goal of this paper is to estimate the capital shortfall of the banking system in a severe adverse scenario while taking the interactions between the financial and real sectors of the economy into account. For this purpose, we develop and estimate a macro-finance dynamic stochastic general equilibrium (DSGE) model in which we introduce two types of banks: deposit banks, which receive deposits from households and provide (risky) loans to merchant banks; and merchant banks, which use short-term loans from deposit banks to buy long-term claims on producing firms' assets. This description of the banking system allows us to capture several key stylized facts. In particular, merchant banks borrow from deposit banks by posting collateral assets, generating an amplification phenomenon if the value of the assets fall. In addition, in a crisis, this mechanism can result in an increase in deposit banks' leverage and a decrease in merchant banks' leverage, as observed in 2008. In this model, capital shortfall is the additional equity that would be necessary for deposit banks to repay their deposits in bad times. We quantify this measure, which we call the stressed expected loss (SEL), by implementing a counterfactual experiment similar to the adverse scenario assumed by the ECB in its stress test. Furthermore, we investigate the case of a cycle-dependent capital ratio (similar to a countercyclical capital buffer promoted in the Basel III regulatory framework) as a way to mitigate the impact of the crisis on economic growth and bank health.

We obtain three important results. First, our model estimates indicate that most of the variability in the macroeconomic and financial variables at business cycle frequencies is due to the investment shock and risk shock. We therefore define a crisis as an adverse combination of these two shocks. Second, when we simulate a crisis similar to that observed in 2008, we generate a substantial increase in the probability of deposit banks' default and consequently in their capital shortfall. Our estimate of the SEL is equal to 2.8\% of GDP, which corresponds to approximately 250 billion euros (see the table below). We also find that a deposit bank's total loss of equity in the crisis is equal to $46 \%$ of its steadystate equity. This number can be compared to the decrease in the market capitalization of European banks between the end of 2007 and the end of 2008 (approximately 50\%). Third, using a standard countercyclical capital ratio that relies on output and credit growth as indicators of the state of the economy allows us to improve welfare at the expense of a more fragile banking system. However, if we consider a capital ratio that combines concern 
for both output or credit growth and SEL, a positive effect on welfare can be attained while mitigating the excessive risk taking in the banking system.

\section{Structure of the model}

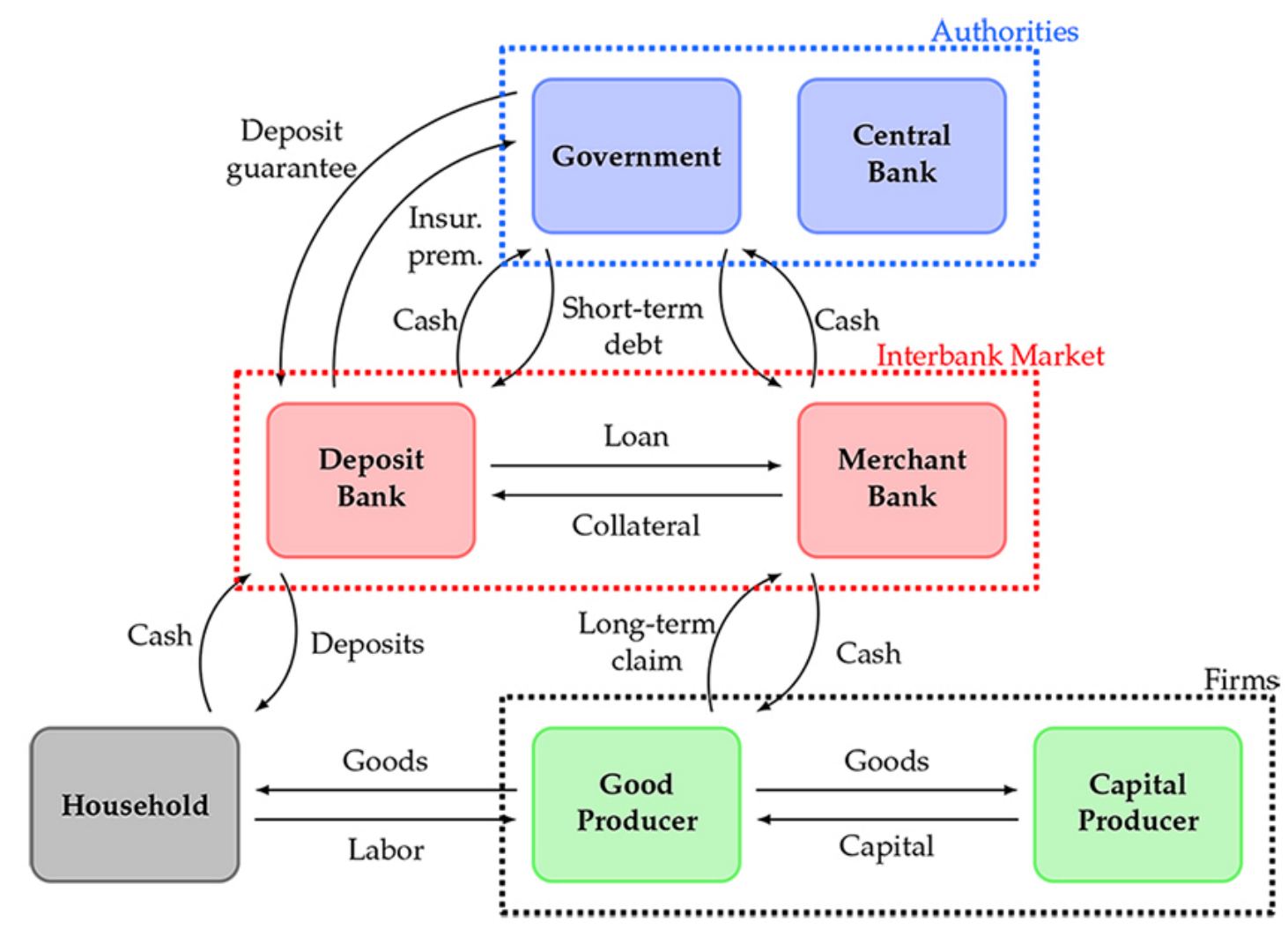

\section{Une évaluation en équilibre général du besoin en capital des banques}

\section{RÉSUMÉ}

Nous quantifions le besoin en capital des banques résultant d'une crise financière en utilisant un modèle DSGE de macro-finance qui tient compte des interactions entre les secteurs financier et réel de l'économie. Nous trouvons qu'une crise similaire à celle observée en 2008 engendre un besoin en capital (ou stressed expected loss, SEL) égal à 2,8\% du PIB de la zone euro, ce qui correspond à environ 250 milliards d'euros. Nous montrons que l'utilisation d'un ratio de capital dépendant du cycle qui répond à la fois à la croissance du crédit et du SEL a un effet positif sur la croissance économique tout en atténuant la prise de risque excessive du système bancaire. Enfin, nos estimations confirment que la plus grande partie de la variabilité des variables macroéconomiques et financières à la fréquence du cycle d'affaires provient des chocs d'investissement et de risque.

Mots-clés : besoin en capital, des banques, risque systémique, levier, système financier, zone euro, modèle DSGE.

Les Documents de travail reflètent les idées personnelles de leurs auteurs et n'expriment pas nécessairement la position de la Banque de France. Ils sont disponibles sur publications.banque-france.fr 


\section{Introduction}

A fundamental difference in corporate funding between the euro area and the United States is that European firms rely more heavily on bank lending. ${ }^{1}$ Of all corporate debt in the euro area, $80 \%$ comes from bank lending and $20 \%$ from corporate bond markets, almost the inverse of the situation in the United States. In this context, when a global financial crisis occurs, the safeguard of the bank lending channel may lead to potentially high costs for European taxpayers. In a recent comprehensive assessment combining an asset quality review and a stress test on 130 euro area banks, the European Central Bank (ECB) estimated that in a severely adverse scenario, the lack of capital would be close to 263 billion euros (ECB, 2014). ${ }^{2}$ This assessment, which is performed at individual bank level, requires a massive analysis of bank portfolios, including the valuation of loans and collateral items and the review of valuation models. It is therefore very time consuming and has been performed so far on a biannual basis only. It also suffers from two major drawbacks. First, it evaluates the impact of the scenario on individual bank balance sheets, assuming that banks do not react to the scenario (static balance sheet assumption). Second, and more importantly, it does not take the interaction between the banking system and the rest of the economy into account.

The goal of this paper is to estimate the capital shortfall of the banking system in a severe adverse scenario while taking the interactions between the financial and real sectors of the economy into account. For this purpose, we develop and estimate a macro-finance dynamic stochastic general equilibrium (DSGE) model in which we introduce two types of banks: deposit banks, which receive deposits from households and provide (risky) loans to merchant banks; and merchant banks, which use short-term loans from deposit banks to buy long-term claims on producing firms' assets. This description of the banking system allows us to capture several key stylized facts. In particular, merchant banks borrow from deposit banks by posting collateral assets, generating an amplification phenomenon if the value of the assets fall. In addition, in a crisis, this mechanism can result in an increase in deposit banks' leverage and a decrease in merchant banks' leverage, as observed in 2008.

In this model, capital shortfall is the additional equity that would be necessary for deposit banks to repay their deposits in bad times. We quantify this measure, which we call the

\footnotetext{
${ }^{1}$ The ratio of total bank assets to GDP is approximately $280 \%$ in the euro area and $78 \%$ in the United States, the ratio of bank loans to the corporate sector to GDP is $48 \%$ in the euro area and $19 \%$ in the United States, and the ratio of stock market capitalization to GDP is $52 \%$ in the euro area and $120 \%$ in the United States (see, for instance, Brinkmeyer, 2014).

${ }^{2}$ Using an alternative approach, which considers that the market value of equity reflects market participants' current evaluation of the bank balance sheet, Acharya and Steffen (2014) report estimates of euro area banks' capital shortfall ranging between 230 and 620 billion euros.
} 
stressed expected loss (SEL), by implementing a counterfactual experiment similar to the adverse scenario assumed by the ECB in its stress test. Furthermore, we investigate the case of a cycle-dependent capital ratio (similar to a countercyclical capital buffer promoted in the Basel III regulatory framework) as a way to mitigate the impact of the crisis on economic growth and bank health.

We obtain three important results. First, our model estimates indicate that most of the variability in the macroeconomic and financial variables at business cycle frequencies is due to the investment shock and risk shock. We therefore define a crisis as an adverse combination of these two shocks. Second, when we simulate a crisis similar to that observed in 2008, we generate a substantial increase in the probability of deposit banks' default and consequently in their capital shortfall. Our estimate of the SEL is equal to $2.8 \%$ of GDP, which corresponds to approximately 250 billion euros. We also find that a deposit bank's total loss of equity in the crisis is equal to $46 \%$ of its steady-state equity. This number can be compared to the decrease in the market capitalization of European banks between the end of 2007 and the end of 2008 (approximately 50\%). Third, using a standard countercyclical capital ratio that relies on output and credit growth as indicators of the state of the economy allows us to improve welfare at the expense of a more fragile banking system. However, if we consider a capital ratio that combines concern for both output or credit growth and SEL, a positive effect on welfare can be attained while mitigating the excessive risk taking in the banking system.

The functioning of our model can be summarized as follows. The non-financial side of the model is fairly standard and similar to Smets and Wouters (2007). Firms buy capital equipment from capital producers and produce final goods that are sold to households. They finance their investment in capital equipment by selling a long-term claim on their assets to merchant banks. Merchant banks obtain funds from deposit banks and use the firm's securities as collateral to secure the loan. Their revenues from the firm's securities depend not only on the shock to the firm's capital investment but also on the cross-sectional dispersion in the quality of the capital equipment (Gertler and Kiyotaki, 2010, and Christiano et al., 2014). If the quality is low, the value of merchant banks' assets is low and the collateral may be insufficient to secure the loan. In that case, merchant banks have to delever by selling assets and reduce their debt to match the available collateral (a similar argument is developed in Acharya and Viswanathan, 2011). For some banks, the loss on the firm's securities can be so large that the bank defaults. In such an instance, the remaining assets are liquidated by the deposit banks at a cost. Some deposit banks may have insufficient assets to repay their deposits and therefore 
default. Because deposits are guaranteed by an insurance mechanism, the cost of the deposit

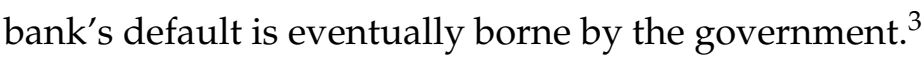

An important ingredient to explain the mechanism of a crisis is the dynamics of the deposit bank's leverage. In a market downturn, the mark-to-market (or fair) value of the assets decreases, whereas deposits must be repaid at their face value. Therefore, the value of the equity decreases due to the loss on the assets, and leverage increases in the short term. This mechanism is illustrated in Figure 1 using aggregate data collected by the ECB. The increase in the leverage of monetary financial institutions was substantial in the euro area during the subprime crisis and again during the sovereign debt crisis. The ratio of total financial assets over equity increased from 8 in 2007 to more than 12 at the end of 2008 and more than 14 in 2012. Similar evidence is reported by He et al. (2010) and He and Krishnamurthy $(2012,2013)$, who find that the leverage of commercial banks increased in 2008, while it had decreased in the years preceding the crisis. In contrast, as illustrated by Adrian and Shin (2010,2014), merchant banks use collateralized debt to partly finance their activities. Therefore, in a crisis, the value of their collateral decreases and they must delever to cover their margin limit. ${ }^{4}$ These contrasting mechanisms are important because they explain how a decrease in returns on securities increases deposit banks' capital shortfall through the eventual default of merchant banks.

We first estimate our model by applying the Bayesian methodology to euro area data covering a relatively normal period (1985-2007) in order to avoid the estimates becoming biased by the zero lower bound episode in the aftermath of the financial crisis. ${ }^{5}$ The variance decomposition indicates that most of the variability in the macroeconomic and financial variables at business cycle frequencies is due to the investment shock and the risk shock, and the impulse response analysis illustrates that the model reproduces most of the stylized facts associated with the variables' dynamics. We then implement a counterfactual experiment that corresponds to an adverse scenario. We consider a combination of two shocks: first, the investment in capital equipment is affected by a large negative shock, which results in a severe contraction of investment and output; second, the cross-sectional dispersion of the quality of capital

\footnotetext{
${ }^{3}$ In the U.S., deposits are guaranteed by the Federal Deposit Insurance Corporation (FDIC) up to a stated limit. The FDIC is funded by bank-paid premiums for deposit insurance coverage. The setup of a deposit insurance scheme in the euro area is still an ongoing process. The European Deposit Insurance Scheme (EDIS), proposed in November 2015, will constitute the third pillar of the banking union. Currently, deposit insurance is based on a system of national deposit guarantee schemes.

${ }^{4}$ Adrian and Shin $(2010,2014)$ provide evidence that U.S. securities brokers and dealers and investment banks dramatically delevered between 2008 and 2009. Aggregate data on securities brokers and dealers and investment banks are not available in the euro area, so we cannot confirm this evidence for European investment banks.

${ }^{5}$ The monetary policy implemented by the ECB after the start of the subprime crisis includes instruments that are not described in the model and that deserve additional investigation (see, for instance, Andrade et al., 2016 and Cahn et al., 2017).
} 
Figure 1: Leverage of monetary financial institutions in the euro area

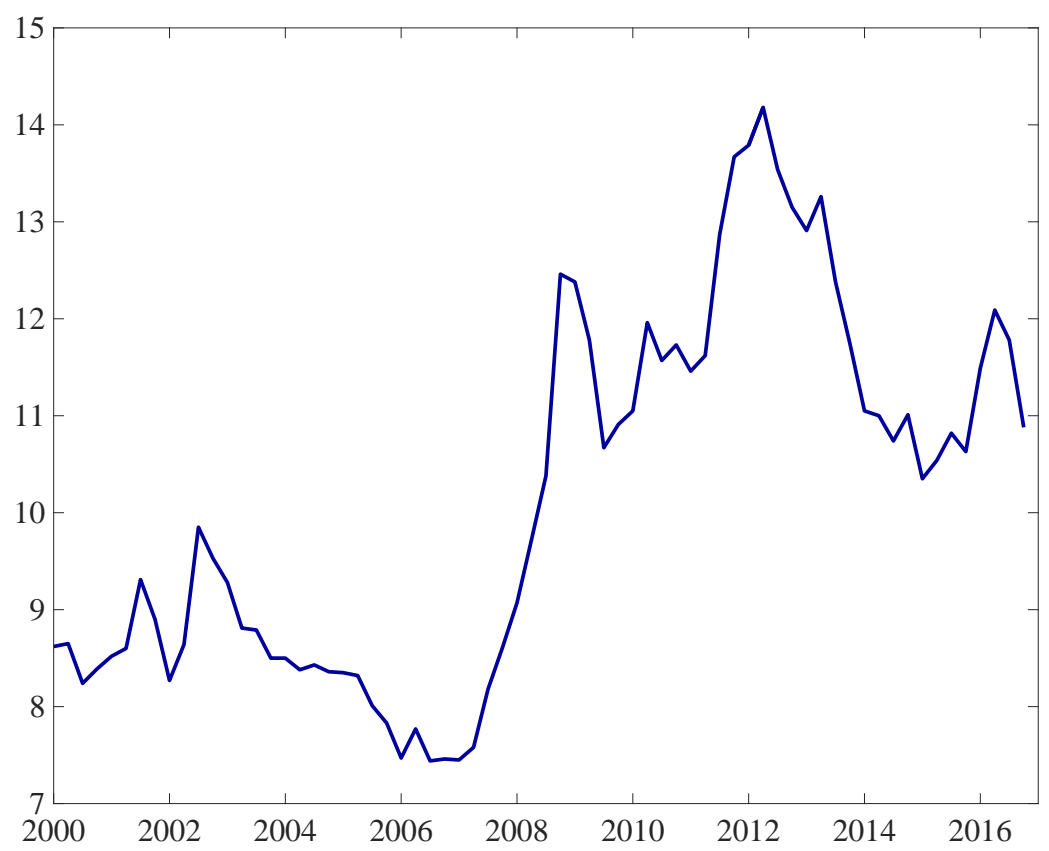

Note: Leverage is defined as the ratio of total financial assets over the equity of monetary financial institutions, from 1999:Q1 to 2016:Q4. Monetary financial institutions include money market funds but exclude the Eurosystem.

Source: Statistical Data Warehouse of the ECB.

equipment is affected by a large positive shock, which induces large losses on the assets of some merchant banks. We find that this scenario, with an amplitude of the crisis similar to that observed in 2008, generates a substantial increase in the probability of default of deposit banks and in aggregate capital shortfall. The magnitude of the capital shortfall is similar to empirical estimates of the equity loss of deposit banks in the subprime crisis or in the recent sovereign debt crisis (Acharya and Steffen, 2014).

Finally, we analyze countercyclical macroprudential rules in this framework and compare different specifications from a welfare perspective. We first illustrate that a countercyclical rule designed to reduce the capital ratio of deposit banks when output or credit growth is below its steady-state level has a contrasting effect. On one hand, it increases bank lending and therefore reduces the impact of the adverse shock. On the other hand, it renders banks more fragile because of the induced increase in leverage. If we consider a rule that combines both a concern for output or credit growth and SEL, we obtain that a positive effect on total growth can be attained while also reducing the excessive risk taking in the banking system. ${ }^{6}$

\footnotetext{
${ }^{6}$ A similar observation is made by Acharya et al. (2012): They measure systemic risk as the systemic expected shortfall (SES) of a financial institution, i.e. its propensity to be undercapitalized when the system as a whole is undercapitalized. They find that taxing institutions based on their SES forces them to internalize their externality arising in a systemic crisis.
} 
Relevant literature. Among the few papers that investigate bank capital shortfall in a theoretical macroeconomic model, our model is closely related to Acharya et al. (2012) and He and Krishnamurthy (2014) because they define capital shortfall in a model-consistent way. ${ }^{7}$ We share with He and Krishnamurthy (2014) the construction of a general equilibrium model of the economy in which non-linearities contribute to capital shortfall. In their paper, capital shortfall is defined as the probability of reaching a state in which capital constraints bind across the financial sector. In contrast, we follow the same definition of capital shortfall as in Acharya et al. (2012), where the externality that generates systemic risk is a financial institution's propensity to be undercapitalized in a crisis, i.e., when the financial system as a whole is undercapitalized. In this context, few financial institutions would likely be willing to absorb liabilities and acquire the failing banks. Acharya et al. (2012) define systemic risk as the expected difference between a fraction of the assets and the bank's equity in the crisis. Our measure of SEL is comparable with the empirical evaluation of their measure provided by Brownlees and Engle (2017). ${ }^{8}$

In our model, most business cycle fluctuations, particularly the occurrence of crises, are driven by the combination of the investment shock and the risk shock. Several recent papers have highlighted the importance of financial shocks, i.e., shocks that may originate in other sectors but affect the financial sector and possibly propagate to other sectors. An important implication of credit market frictions introduced by Bernanke and Gertler (1989), Carlstrom and Fuerst (1989), Kiyotaki and Moore (1997), and Bernanke et al. (1999), among others, is the amplification of these shocks, particularly through leverage and fire sales. Jermann and Quadrini (2012) consider a shock to the recovery rate in the case of a borrower default. Christiano et al. (2014) call risk shock a change in the cross-sectional dispersion in the quality of firms' capital equipment. Gilchrist and Zakrajšek (2012) provide empirical evidence that a shock to the credit spread is a powerful predictor of economic activity. An increase in the credit spread reflects a reduction in the ability of the financial sector to take risks, which re-

\footnotetext{
${ }^{7}$ Martinez-Miera and Suarez (2014) also design a general equilibrium model to investigate the impact of systemic shocks on banks' risk taking. These authors show that capital requirements reduce risk taking at the cost of a reduction in credit and output. Jondeau and Khalilzadeh (2017) define and measure SEL in a calibrated real business cycle model of the U.S. economy.

${ }^{8}$ Some papers have proposed measures of capital shortfall based on the evoluation of the balance sheet of financial institutions in a market downturn. Jobst and Gray (2013) measure systemic risk based on contingent claims analysis. They construct a risk-adjusted balance sheet based on option pricing theory. In their approach, a fall in the value of assets increases expected losses to creditors and results in a less than one-to-one decline in the market value of equity. Huang et al. (2011) measure systemic risk as the price of insurance against financial distress. Their distressed insurance premium can be viewed as the theoretical premium to a risk-based deposit insurance scheme that guarantees against severe losses for the banking system.
} 
sults in credit supply contraction. Brunnermeier and Sannikov (2014) show that large shocks can generate severe economic crises due to highly nonlinear amplification effects.

Our paper is also related to the growing literature that investigates the implementation of macroprudential policy in the context of a DSGE model. Several papers, including Alpanda et al. (2014), Angelini et al. (2014), Rubio and Carrasco-Gallego (2014), and Collard et al. (2017), analyze the interaction and possible complementarity between monetary policy and macroprudential policy. Recently, Angeloni and Faia (2013) and Gelain and Ilbas (2017) evaluate the benefits of coordinating monetary and macroprudential policies through alternative coordination schemes. Clerc et al. (2015) investigate welfare implications of normative and positive macroprudential policies. Macroprudential rules consider different instruments, such as bank leverage and the capital ratio (Angelini et al., 2014), the loan-to-value ratio (Rubio and Carrasco-Gallego, 2014), or the bank capital tax (Gelain and Ilbas, 2017). However, there is broad consensus regarding the indicators used in the policy rule: most of the literature considers the output gap (or output growth) and the credit-to-GDP ratio (or credit growth). See Galati and Moessner (2012) for a recent survey.

The rest of the paper is organized as follows. In Section 2, we describe the new theoretical aspects introduced in the model and their main mechanisms. In Section 3, we provide details about the estimation of the model and present the dynamic properties of the model. In Section 4, we provide an analytical and quantitative analysis of the SEL as a measure of capital shortfall in a crisis. In particular, we illustrate how it can be used as an important indicator in a macroprudential policy rule. Section 5 concludes.

\section{Model Overview}

Because most of the aspects of household, production, and public sectors in our model are fairly standard and close to Smets and Wouters (2003, 2007) and Justiniano et al. (2010), we begin with a summary of the main characteristics of the non-financial sectors. In contrast, because the modeling of the banking sector provides several new insights, we provide a more comprehensive description of this sector. Figure 2 summarizes the main relations of the model. In Appendix A, we provide a complete description of the model.

\subsection{Standard Part of the Model}

The economy is inhabited by a continuum of differentiated households. We adopt the large family assumption of Merz (1995) and Andolfatto (1996) by assuming that each household con- 
Figure 2: Structure of the Model

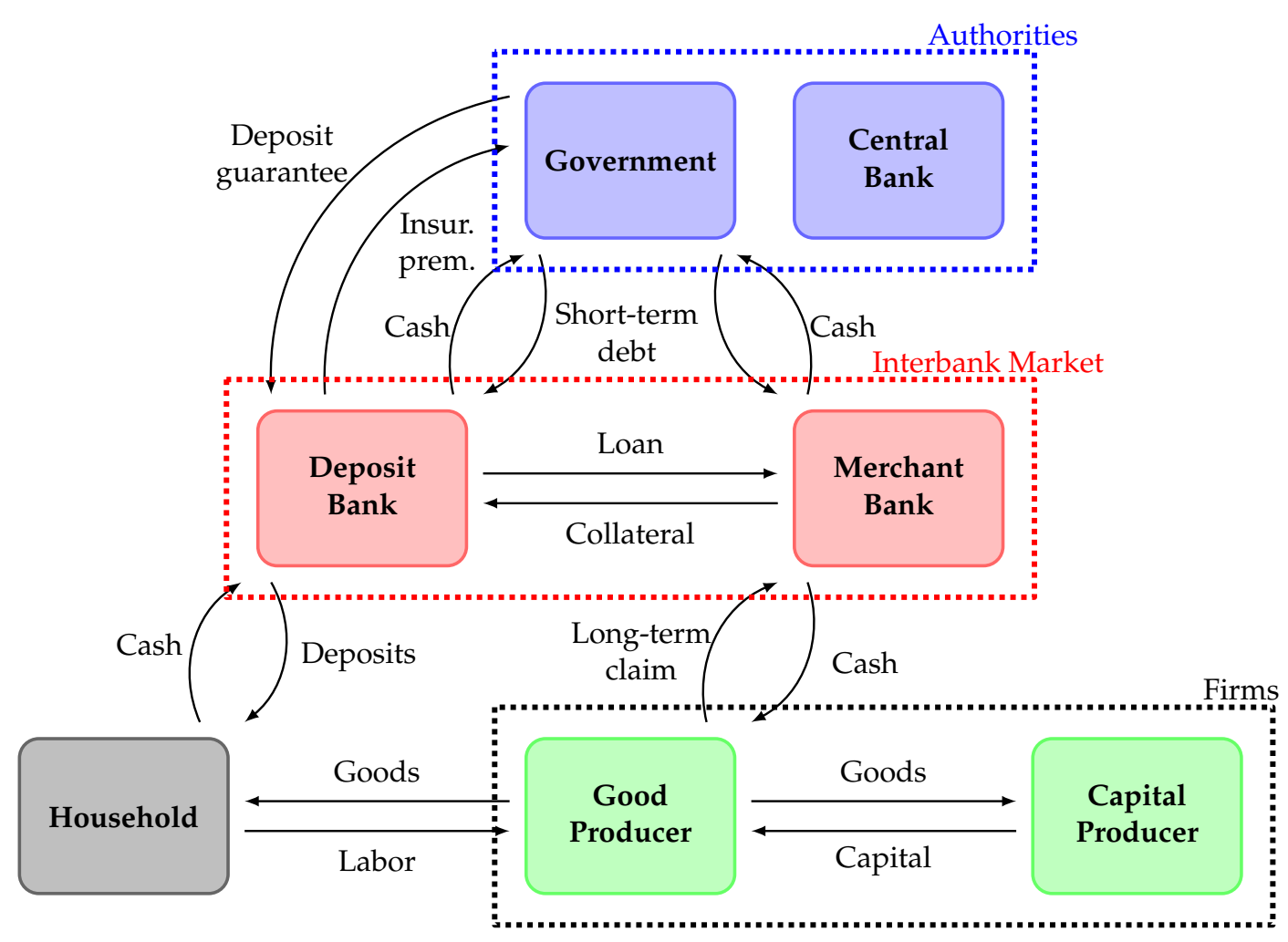

tains every type of differentiated labor. The utility function has a standard habit-in-consumption specification. A typical household maximizes its expected utility by selecting the consumption, labor, and deposit sequence. It pays taxes and receives nominal transfers from the government and family members. Because the deposit bank can default, deposits are guaranteed by the government according to the following mechanism: the deposit bank pays a risk-free deposit rate to the household and an insurance premium to the government; the insurance premium is determined at equilibrium to cover the expected loss to depositors in case of a deposit bank's default.

Each household is a monopolistic supplier of specialized labor. Many competitive employment agencies combine households' labor into a homogeneous labor input that is sold to firms. Because households have market power on their labor, wages are set according to a staggering mechanism. In each period, a fraction of households cannot choose their wage optimally but adjust it to keep up with the increase in the general wage level in the previous period, according to an indexation rule. The remaining fraction of workers instead choose the optimal wage subject to the labor demand function.

Intermediate goods producers are competitive firms that use a constant returns to scale technology to produce intermediate goods that are sold to retailers. Each firm finances its 
capital acquisition by obtaining funds from a merchant bank, which invests in only one project. As in Bernanke et al. (1999) and Gertler and Kiyotaki (2010), the firm sells to the bank a longterm claim on its future cash flows equal to the value of the capital units acquired. Given that the firm earns zero profit state by state, it simply pays out the ex post return to capital to the merchant bank. ${ }^{9}$

After all agents have made their decisions, the quality of capital is revealed to the firm through the realization of an idiosyncratic shock. This shock is drawn independently across firms. Following Christiano et al. (2014), the cross-sectional dispersion of this idiosyncratic shock varies through time and plays the role of a risk shock. Because the investment is financed one period in advance - before the firm-specific shock is realized - the gross nominal rate of return on the bank's investment made at date $t$ is not known until the end of the period.

Capital goods producers are competitive firms that buy back old capital units and add a fraction of the final good as input (subject to adjustment costs) to produce the new capital units. New capital is sold to intermediate goods producers.

Price rigidities are introduced into the model by assuming that a continuum of monopolistic retail firms purchase intermediate goods before transforming them into a continuum of differentiated goods without costs. The retail firm sets its price according to a staggering mechanism. In each period, a fraction of firms cannot choose its price optimally but adjust it to keep up with the increase in the general price level in the previous period according to an indexation rule. The remaining fraction of firms choose the price optimally by maximizing the present discounted value of future profits.

Government spending, net transfers, and interest payments are financed by short-term government bonds sold to banks, consumption, labor income, and capital taxes. The government also receives the insurance premium from the deposit bank to guarantee the household's deposits and pays the capital shortfall in the case of bank default. We provide more details on how the insurance premium is determined in Section 2.2.2. Monetary authorities follow a generalized Taylor rule by gradually adjusting the nominal interest rate in response to inflation and output growth.

A minimum capital requirement is imposed on the deposit bank. Consistent with the Basel II regulatory framework, we assume in our baseline calibration that the capital ratio is equal to $8 \%$, which means that bank equity should represent at least $8 \%$ of its risk-weighted assets.

\footnotetext{
${ }^{9}$ The long-term claim can be viewed in the model as a long-term state contingent loan (typically, a perpetuity) or as a share of equity of the firm. The important feature of these securities is that the next-period value of the claim depends on the firm's performance. As in Gertler and Kiyotaki (2010), we therefore assume that there is no agency cost in the merchant bank/firm relationship. Considering a standard long-term debt would introduce an additional layer of defaulting agent, as in Clerc et al. (2015).
} 
In Section 4.6, we consider a version of the model in which the regulatory capital ratio is made dependent on the state of the economy.

\subsection{Banking Sector}

We introduce two types of banks in the model to describe the two main activities of the banking sector: (1) the deposit bank receives deposits from households and invests in risky assets; and (2) the merchant bank uses a short-term loan from the deposit bank to buy a long-term claim on the producing firm's assets. Although the terminology may differ across papers, several models have two types of financial intermediaries. For instance, Dib (2010) discusses lending and saving banks, while Nuño and Thomas (2017) study banks and institutional investors and Begenau and Landvoigt (2016) focus on commercial and shadow banks. We keep the terminology introduced by De Walque et al. (2010): merchant and deposit banks. An important mechanism for merchant banks is their reliance on short-term funds to finance their longterm investment. In addition, following the recent trend in the banking industry, most of these short-term funds are collateralized, as put forward by Adrian and Shin $(2010,2014)$ for securities brokers and dealers or investment banks. ${ }^{10}$

\subsubsection{Merchant Bank}

The merchant bank buys a long-term claim issued by the firm $\left(S_{t}\right)$ to finance its capital equipment. The gross nominal return on this investment is denoted by $\tilde{R}_{s, t}$, where the tilde means that the return over period $t$ is known only at the end of the period.

The merchant bank optimally determines the fraction of its equity $\left(a_{m, t} \in[0,1]\right)$ used to buy the firm's securities. The rest is financed by a loan from the deposit bank. Following current practice, we assume that the loan is secured: firm securities are used as collateral to cover the deposit bank's potential loss in the case of the merchant bank's default. The fraction of the investment financed by the loan is determined by the margin rate, or haircut, denoted by h. ${ }^{11}$ The value of the loan is given by $B_{t}=S_{t} /(1+\mathrm{h})$, so that the value of the equity needed to secure the loan is $a_{m, t} N_{m, t}=S_{t} \mathrm{~h} /(1+\mathrm{h})$. The unencumbered (or free) cash that is kept by the merchant bank as a buffer in case of a margin call is defined as $M_{m, t}=\left(1-a_{m, t}\right) N_{m, t}$. The

\footnotetext{
${ }^{10}$ The merchant bank could be viewed as an entrepreneur as in Christiano et al. (2014) or Clerc et al. (2015). However, the merchant bank naturally relies on collateralized loans to build leverage. This mechanism allows the banking system to finance the economy at a relatively low cost in normal time, but with potentially dramatic consequences in a financial crisis.

${ }^{11}$ The difference between the value of the loan and the value of the collateral, denoted as the margin (or haircut), must be financed with the bank equity. We assume that the value of the margin rate is fixed. Alternatively, the margin rate could be determined by the deposit bank to cover the potential loss on its loan to the merchant bank. See Brunnermeier and Pedersen (2009).
} 
balance sheet is therefore determined by the value of firm securities $\left(S_{t}\right)$, the margin rate $(\mathrm{h})$, and the optimal fraction of equity kept in cash $\left(1-a_{m, t}\right)$.

\section{Balance sheet of a merchant bank in equilibrium}

\begin{tabular}{ll|ll} 
Assets & & \multicolumn{2}{|l}{ Liabilities and Equity } \\
\hline Cash: & $M_{m, t}=\frac{\mathrm{h}\left(1-a_{m, t}\right)}{(1+\mathrm{h}) a_{m, t}} S_{t}$ & Debt: $\quad B_{t}=\frac{1}{1+\mathrm{h}} S_{t}$ \\
Securities: & $S_{t}$ & Equity: $\quad N_{m, t}=\frac{\mathrm{h}}{(1+\mathrm{h}) a_{m, t}} S_{t}$
\end{tabular}

The accounting of the balance sheet implies the following expression for the merchant bank equity at the end of period $t$ :

$$
N_{m, t+1}=\tilde{R}_{s, t} S_{t}+R_{t} M_{m, t}-R_{b, t} B_{t}=\left[\tilde{R}_{s, t} \frac{a_{m, t}(1+\mathrm{h})}{\mathrm{h}}+R_{t}\left(1-a_{m, t}\right)-R_{b, t} \frac{a_{m, t}}{\mathrm{~h}}\right] N_{m, t}
$$

where the risk-free rate $\left(R_{t}\right)$ and the interbank rate $\left(R_{b, t}\right)$ are fixed one period in advance for the merchant bank, whereas the return on securities $\left(\tilde{R}_{s, t}\right)$ is observed only at the end of the period.

Depending on the return on the firm's investment $\left(\tilde{R}_{s, t}\right)$, the merchant bank faces three different situations. If $\tilde{R}_{s, t}$ is high enough, the value of the securities represents a sufficient collateral to secure the loan. However, when the return on investment is lower, the value of collateral may fall below the level requested by the deposit bank. In this case, the merchant bank can use part of its cash buffer to reduce its debt so that it does not have to liquidate its risky positions (Case 1, good conditions). Below a given threshold, which we denote by $\bar{R}_{s, t}$, the merchant bank has exhausted all its free cash and must sell a fraction of its securities to reduce its debt so that the new level of debt is consistent with available collateral: $\tilde{R}_{s, t} S_{t}=$ $(1+\mathrm{h}) B_{t}$. As the bank sells securities with short notice (fire sale), it incurs a cost proportional to the value of securities sold, where $\phi \in[0,1]$ denotes the cost per unit (Case 2, fire sales). Below another threshold, denoted by $\underline{R}_{s, t}$, even by selling all firm securities, the merchant bank cannot meet the request for collateral and therefore defaults (Case 3, default). The following proposition provides the expression for the expected equity of the merchant bank.

Proposition 1. The expected value of the equity of the merchant bank is

$$
\mathrm{E}_{t}\left[N_{m, t+1}\right]=\underbrace{\mathrm{E}_{t}\left[N_{m, t+1}^{(\text {good })}\right] \times \operatorname{Pr}\left[\tilde{R}_{s, t}>\bar{R}_{s, t}\right]}_{\text {Case 1: good conditions }}+\underbrace{\mathrm{E}_{t}\left[N_{m, t+1}^{(\text {fire })}\right] \times \operatorname{Pr}\left[\tilde{R}_{s, t} \in\left[\underline{R}_{s, t}, \bar{R}_{s, t}\right]\right]}_{\text {Case 2: fire sales }},
$$


where the expected equity under the different cases is given by

$$
\begin{aligned}
\mathrm{E}_{t}\left[N_{m, t+1}^{(\text {good })}\right] & =\left[\mu_{s, t}^{(\text {good })} \frac{a_{m, t}(1+\mathrm{h})}{\mathrm{h}}+R_{t}\left(1-a_{m, t}\right)-R_{b, t} \frac{a_{m, t}}{\mathrm{~h}}\right] N_{m, t}, \\
\mathrm{E}_{t}\left[N_{m, t+1}^{(\text {fire })}\right] & =\frac{1+\mathrm{h}}{(1+\mathrm{h})(1-\phi)-1}\left[\mu_{s, t}^{(f i r e)}(1-\phi) a_{m, t}+R_{t} \frac{\mathrm{h}\left(1-a_{m, t}\right)}{1+\mathrm{h}}-R_{b, t} \frac{a_{m, t}}{1+\mathrm{h}}\right] N_{m, t},
\end{aligned}
$$

where $\mu_{s, t}^{(\text {good })}=\mathrm{E}_{t}\left[\tilde{R}_{s, t} \mid \tilde{R}_{s, t}>\bar{R}_{s, t}\right]$ and $\mu_{s, t}^{(\text {fire })}=\mathrm{E}_{t}\left[\tilde{R}_{s, t} \mid \tilde{R}_{s, t} \in\left[\underline{R}_{s, t}, \bar{R}_{s, t}\right]\right]$ denote the expected return on firm's securities in good conditions and in a fire sale, respectively. The thresholds between the different cases are $\underline{R}_{s, t}=\frac{1}{(1+\mathrm{h})(1-\phi)}\left(R_{b, t}-R_{t} \frac{\mathrm{h}\left(1-a_{m, t}\right)}{a_{m, t}}\right)$ and $\bar{R}_{s, t}=(1-\phi) \underline{R}_{s, t}$, with $\underline{R}_{s, t}<\bar{R}_{s, t}<0$.

Proof: See Appendix A.4.1, which provides details on the three cases that can arise.

The bank determines the optimal fraction of its equity invested in firm's securities $\left(a_{m, t}\right)$ so as to maximize its expected equity. Because portfolio adjustment can be costly, we allow a quadratic cost when the bank rebalances its portfolio of risky assets between dates $t$ and $t+1$. The intertemporal optimization program is

$$
\max _{\left\{a_{m, t}\right\}} \mathrm{E}_{t} \sum_{s=0}^{\infty} \beta^{s} \frac{\Lambda_{t+s}}{\Lambda_{t}}\left[N_{m, t+s}-\frac{\psi_{m}}{2}\left(\frac{a_{m, t+s}}{a_{m, t+s-1}}-1\right)^{2} a_{m, t+s} N_{m, t+s}\right],
$$

where $\Lambda_{t}$ denotes the marginal utility of consumption and $\psi_{m}$ is the adjustment cost parameter. Merchant bank's leverage is defined as $\operatorname{Lev}_{m, t}=\left(B_{t}+N_{m, t}\right) / N_{m, t}=\left(1+a_{m, t}\right) / \mathrm{h}$, and its probability of default is $\Pi_{m, t}=\operatorname{Pr}\left[\tilde{R}_{s, t} \leq \underline{R}_{s, t}\right] \equiv \Phi_{s}\left(\underline{R}_{s, t}\right)$, where $\Phi_{s}$ denotes the cdf of $\tilde{R}_{s, t} .12$ Leverage increases with the fraction $a_{m, t}$ of equity invested in firm securities and decreases with the margin rate $h$. The main amplification mechanism is driven by the collateralization of the merchant bank's debt. In case of a fall in securities prices, the merchant bank must delever at additional cost (fire sale), which can reinforce the loss incurred by the banking system. The impact of the market crisis could be further amplified by introducing a haircut that would increase in bad time. We address this question in Section 4.5 by investigating the impact on the economy of a change in the haircut value.

\footnotetext{
${ }^{12}$ Following Bernanke et al. (1999), Gertler and Kiyotaki (2010), and Christiano et al. (2014), we assume that the firm-specific shock to the quality of capital $\left(\omega_{t}\right)$ has a log-normal cross-sectional distribution. Therefore, the rate of return on firm securities $\tilde{R}_{s, t}$ is also log-normally distributed with $\mu_{s, t}=\mathrm{E}_{t}\left[\log \left(\tilde{R}_{s, t}\right)\right]$ and $\sigma_{s, t}^{2}=\mathrm{V}_{t}\left[\log \left(\tilde{R}_{s, t}\right)\right]$ the cross-sectional expected return and dispersion of the securities' log-returns in period $t$, respectively. Expressions to compute probabilities and conditional expected returns are given in Appendix A.4.1.
} 


\subsubsection{Deposit Bank}

The deposit bank receives deposits $\left(D_{t}\right)$ from households and provides a loan $\left(B_{t}\right)$ to the merchant bank. A default of the merchant bank would cause the deposit bank to incur a loss on the loan. This potential loss is compensated in equilibrium by a risk premium paid by the merchant bank on its loan. However, in the case of a merchant bank's default, if the deposit bank has too much exposure to the loan, it may be unable to repay deposits to households, inducing its own default.

To mitigate this risk of default, the deposit bank holds a cash buffer that can be used to repay deposits. The optimal cash buffer is determined as a fraction of the deposits $M_{d, t}=$ $\left(1-a_{d, t}\right) D_{t}$, with $a_{d, t} \in[0,1]$, so as to maximize its expected equity. The equity at the beginning of period $t$ is therefore given by $N_{d, t}=M_{d, t}+B_{t}-D_{t}=B_{t}-a_{d, t} D_{t}$.

Several aspects of a deposit bank are not described in this model. First, in actual data, deposit banks are involved in the financing of non-financial corporations in two ways: directly through corporate loans and indirectly through loans to other financial institutions (for a total of $50 \%$ of the total assets of monetary financial institutions in the euro area). The loan to the merchant bank intends to capture both channels. Second, a significant fraction of the deposit bank's assets corresponds to activities that we do not explicitly describe in the model. In particular, the long-term financing of households (mortgages and consumer credits) represents approximately $25 \%$ of total assets. Third, a significant fraction of the deposit bank's financing relies on debt (approximately 15\% of total liabilities). Accounting for these various aspects is not the main purpose of the paper, and therefore, they are not explicitly described in the model. However, they matter to obtain realistic values of deposit bank's leverage and capital ratio. For this reason, we add "other assets" and "other liabilities" categories to the deposit bank's balance sheet, which we denote by $O A_{t}$ and $O L_{t}$, respectively. We assume that the other assets represent a fixed fraction of the total assets and are financed by other liabilities such that $O A_{t}=O L_{t}=\mathscr{\omega}\left(M_{d, t}+B_{t}\right)$. Therefore, $O A_{t}$ represents a fraction $\omega /(1+\omega)$ of total assets, where $\omega$ is determined such that in the steady state, the deposit bank's leverage approximately matches actual data.

The deposit bank faces regulatory capital constraints. The equity of the bank must be larger or equal to a given fraction $\vartheta$ of its risk-weighted assets: $N_{d, t} \geq \vartheta\left(w_{m} M_{d, t}+w_{b} B_{t}+w_{o} O A_{t}\right)$, where $w_{i}$ denotes the risk weight set by the regulator for asset category $i$, for $i=m, b, o$. Because we also have $N_{d, t}=B_{t}-a_{d, t} D_{t}$, the value of the interbank loan that satisfies the capital 
requirement is

$$
B_{t}=\frac{a_{d, t}+\vartheta \omega w_{o}\left(1-a_{d, t}\right)}{1-\vartheta\left(w_{b}+\omega w_{o}\right)} D_{t}
$$

By definition, $w_{m}=0$ because cash is risk-free, and we assume that the risk weight of the loan to the merchant bank is $w_{b}=100 \%$. The risk weight of other assets $\left(w_{0}=150 \%\right)$ is determined such that, in the steady state, restriction (1) is consistent with the margin rate, i.e., $B_{t}=S_{t} /(1+\mathrm{h})$. The balance sheet of the deposit bank is summarized below.

\section{Balance sheet of a deposit bank in equilibrium}

\begin{tabular}{ll|ll} 
Assets & & \multicolumn{2}{|l}{ Liabilities and Equity } \\
\hline Cash: & $M_{d, t}=\left(1-a_{d, t}\right) D_{t}$ & Deposits: & $D_{t}$ \\
Loan: & $B_{t}=S_{t} /(1+\mathrm{h})$ & Other liabilities: & $O L_{t}=O A_{t}$ \\
Other assets: & $O A_{t}=\omega\left(M_{d, t}+B_{t}\right)$ & Equity: & $N_{d, t}=B_{t}-a_{d, t} D_{t}$
\end{tabular}

The interest rate paid by the bank on its deposits $\left(R_{d, t}=R_{t}+\Pi_{i n s, t}\right)$ includes the insurance premium paid to the government. Even if the interest rate on cash $\left(R_{t}\right)$ is lower than the cost of deposits $\left(R_{d, t}\right)$, the deposit bank is incentivized to hold a cash buffer, which reduces its probability of default in case of a loss in the value of the loan. Ex post the return on the loan may be lower than the face value rate $R_{b, t}$ if the merchant bank defaults. We denote by $\tilde{R}_{b, t}$ the ex-post return received by the deposit bank.

When the securities return is above $\underline{R}_{s, t}$, the merchant bank does not default and the loan is fully repaid. Therefore, the value of the deposit bank's assets at the end of period $t$ is

$$
N_{d, t+1}=R_{t}\left(1-a_{d, t}\right) D_{t}+R_{b, t} B_{t}-R_{d, t} D_{t}
$$

In this case, there is no uncertainty in the revenues of the bank because the return on the loan corresponds to the face value rate (Case 1', normal conditions).

When $\tilde{R}_{s, t}<\underline{R}_{s, t}$, the merchant bank defaults and the deposit bank liquidates the remaining assets. The deposit bank incurs a liquidation cost proportional to the value of the liquidated assets, where $\xi \in[0,1]$ denotes the cost per unit. If the securities return is above another threshold, which we denote by $\underline{R}_{s d, t}$, the deposit bank survives because it has sufficient cash to repay the deposits (Case 2', deposit bank survival). Finally, when $R_{s, t}<\underline{R}_{s d, t}$, the loss on the loan is so large that the deposit bank itself defaults (Case $3^{\prime}$, deposit bank default). The following proposition provides the expression for the expected equity of the deposit bank. 
Proposition 2. The expected value of the deposit bank's equity is

$$
\mathrm{E}_{t}\left[N_{d, t+1}\right]=\underbrace{\mathrm{E}_{t}\left[N_{d, t+1}^{(\text {norm })}\right] \times \operatorname{Pr}\left[\tilde{R}_{s, t}>\underline{R}_{s, t}\right]}_{\text {Case 1': normal conditions }}+\underbrace{\mathrm{E}_{t}\left[N_{d, t+1}^{(\text {survd })}\right] \times \operatorname{Pr}\left[\tilde{R}_{s, t} \in\left[\underline{R}_{s d, t}, \underline{R}_{s, t}\right]\right]}_{\text {Case 2': deposit bank's survival }},
$$

where the expected equity in the different cases is given by

$$
\begin{aligned}
& \mathrm{E}_{t}\left[N_{d, t+1}^{(\text {norm })}\right]=R_{t}\left(1-a_{d, t}\right) D_{t}+R_{b, t} B_{t}-R_{d, t} D_{t}, \\
& \mathrm{E}_{t}\left[N_{d, t+1}^{(\text {survd })}\right]=R_{t}\left(1-a_{d, t}\right) D_{t}+\mu_{b, t}^{(\text {survd })} B_{t}-R_{d, t} D_{t},
\end{aligned}
$$

with $\mu_{b, t}^{(\text {survd })}=\mathrm{E}_{t}\left[\tilde{R}_{b, t} \mid \tilde{R}_{s, t} \in\left[\underline{R}_{s d, t}, \underline{R}_{s, t}\right]\right]=\mu_{s, t}^{(\text {survd })}(1+\mathrm{h})(1-\xi)+R_{t}\left(\mathrm{~h}\left(1-a_{m, t}\right) / a_{m, t}\right) d e-$ notes the expected return on the loan and $\mu_{s, t}^{(\text {survd })}=\mathrm{E}_{t}\left[\tilde{R}_{s, t} \mid \tilde{R}_{s, t} \in\left[\underline{R}_{s d, t}, \underline{R}_{s, t}\right]\right]$ the expected return on firm's securities that correspond to a deposit bank's survival after a merchant bank's default. The threshold between the deposit bank's survival and default cases is $\underline{R}_{s d, t}=\frac{1}{1-\xi}\left[R_{d, t} D_{t}-R_{t}\left(M_{m, t}+M_{d, t}\right)\right] \frac{1}{S_{t}}$, when $\underline{R}_{s d, t}<\underline{R}_{s, t}$ and $\underline{R}_{s d, t}=\underline{R}_{s, t}$ otherwise.

Proof: Appendix A.4.2.

The optimization program of the deposit bank consists of finding the fraction of its deposits $a_{d, t}$ invested in risky assets to maximize its expected equity. We also allow for a quadratic adjustment cost when the deposit bank rebalances its portfolio of risky assets so that the bank solves

$$
\max _{\left\{a_{d, t+s}\right\}} \mathrm{E}_{t} \sum_{s=0}^{\infty} \beta^{s} \frac{\Lambda_{t+s}}{\Lambda_{t}}\left[N_{d, t+s}-\frac{\psi_{d}}{2}\left(\frac{a_{d, t+s}}{a_{d, t+s-1}}-1\right)^{2} a_{d, t+s} D_{t+s}\right],
$$

where $\psi_{d}$ denotes the adjustment cost parameter.

Everything else equal, the deposit bank's probability of default, $\Pi_{d, t}=\operatorname{Pr}\left[\tilde{R}_{s, t} \leq \underline{R}_{s d, t}\right]$, increases with the liquidation cost $\xi$ and the fraction $a_{d, t}$ of deposits invested in risky assets and decreases with the amount of cash held by the merchant bank and the margin rate $h$. Therefore, an increase in the margin rate will result in a lower probability of default for both types of banks.

\subsubsection{Equilibrium Interbank Rate}

We now describe how the interbank rate, $R_{b, t}$, is determined at the beginning of period $t$. Because the loan is risky for the deposit bank in case of a merchant bank's default, the risk premium that the merchant bank has to pay covers the expected loss incurred by the deposit bank. In the case of a merchant bank's default, the deposit bank seizes and liquidates the assets of the merchant bank such that the ex post return on the loan is $\tilde{R}_{s, t}(1+\mathrm{h})(1-\xi)-R_{t} \frac{\mathrm{h}\left(1-a_{m, t}^{*}\right)}{a_{m, t}^{*}}$. 
At equilibrium the interbank rate is equal to the risk-free rate plus a risk premium that covers the expected loss:

$$
R_{b, t}=R_{t}+\left[R_{b, t}-\mu_{s, t}^{(d e f m)}(1+\mathrm{h})(1-\xi)-R_{t} \frac{\mathrm{h}\left(1-a_{m, t}^{*}\right)}{a_{m, t}^{*}}\right] \Phi_{s}\left(\underline{R}_{s, t}\right),
$$

where $\mu_{s, t}^{(\text {defm })}=\mathrm{E}_{t}\left[\tilde{R}_{s, t} \mid \tilde{R}_{s, t} \leq \underline{R}_{s, t}\right]$ depends on $a_{d, t}^{*}$ through $\underline{R}_{s d, t}$. The optimal decisions of the merchant bank $\left(a_{m, t}^{*}\right)$ and the deposit bank $\left(a_{d, t}^{*}\right)$ must be consistent with the equilibrium interbank rate.

\subsubsection{Deposit Insurance Premium}

To determine the equilibrium insurance premium paid by the deposit bank, we now assume that the merchant bank defaults and that the deposit bank cannot fully repay its deposits $\left(\tilde{R}_{s, t} \leq \underline{R}_{s d, t}\right)$. The expected value of the deposits that the bank can repay at $t+1$ is

$$
\mathrm{E}_{t}\left[D_{t+1}^{(d e f d)}\right]=\mathrm{E}_{t}\left[D_{t+1} \mid \tilde{R}_{s, t} \leq \underline{R}_{s d, t}\right]=\left[\mu_{s, t}^{(d e f d)}(1-\xi) S_{t}+R_{t} M_{m, t}\right]+R_{t} M_{d, t},
$$

where the first term corresponds to the value of the liquidated assets of the merchant bank and the second term to the cash buffer held by the deposit bank, with $\mu_{s, t}^{(d e f d)}=\mathrm{E}_{t}\left[\tilde{R}_{s, t} \mid \tilde{R}_{s, t} \leq \underline{R}_{s d, t}\right]$. Therefore, the expected loss, or capital shortfall in a default, is

$$
\begin{aligned}
C S_{d, t} & =\mathrm{E}_{t}\left[R_{d, t} D_{t}-D_{t+1}^{(d e f d)}\right] \Phi_{s}\left(\underline{R}_{s d, t}\right) \\
& =\left[R_{d, t} D_{t}-\mu_{s, t}^{(d e f d)}(1-\xi) S_{t}-R_{t}\left(M_{m, t}+M_{d, t}\right)\right] \Phi_{s}\left(\underline{R}_{s d, t}\right) .
\end{aligned}
$$

The insurance premium paid by the deposit bank to the government to cover the expected loss on deposits in case of default is therefore defined as $\prod_{i n s, t}=C S_{d, t} / D_{t}$.

\subsubsection{Dynamics of Bank Equity}

Because both types of banks can default, we now discuss the dynamics of the number of banks and these banks' aggregate equity. We assume a stationary equilibrium in which defaulting banks are replaced by new banks (see Gertler and Karadi, 2011). Households invest in the equity of the new banks. The proportion of merchant banks and deposit banks that default are defined as $\Pi_{m, t} \equiv \operatorname{Pr}\left[\tilde{R}_{s, t} \leq \underline{R}_{s, t}\right]$ and $\Pi_{d, t} \equiv \operatorname{Pr}\left[\tilde{R}_{s, t} \leq \underline{R}_{s d, t}\right]$, respectively. We also denote the dividend payout of the merchant banks and deposit banks by $\eta_{m, t}$ and $\eta_{d, t}$, respectively. 
We also assume that the new banks are funded with the same value of equity as the continuing ones. The aggregate value of the equity of banks of type $i=m, d$ is therefore

$$
N_{i, t+1}=\underbrace{\left(1-\Pi_{i, t}\right)\left[\left(1-\eta_{i, t}\right) \tilde{R}_{N_{i}, t} N_{i, t}\right]}_{\text {continuing banks }}+\underbrace{\prod_{i, t}\left[\left(1-\eta_{i, t}\right) \tilde{R}_{N_{i, t}} N_{i, t}\right]}_{\text {new banks }}=\left(1-\eta_{i, t}\right) \tilde{R}_{N_{i, t}} N_{i, t},
$$

where $\tilde{R}_{N_{m}, t}=\mathrm{E}_{t}\left[\frac{N_{m, t+1}}{N_{m, t}} \mid \tilde{R}_{s, t}>\underline{R}_{s, t}\right]$ and $\tilde{R}_{N_{d, t}}=\mathrm{E}_{t}\left[\frac{N_{N_{d, t+1}}}{N_{d, t}} \mid \tilde{R}_{s, t}>\underline{R}_{s d, t}\right]$.

Households receive $\left(1-\Pi_{i, t}\right) \eta_{i, t} \tilde{R}_{N_{i, t}} N_{i, t}$ in dividends from the continuing banks and invest $\Pi_{i, t}\left(1-\eta_{i, t}\right) \tilde{R}_{N_{i}, t} N_{i, t}$ in the new banks' equity so that their net revenue is $\left(\eta_{i, t}-\Pi_{i, t}\right) \tilde{R}_{N_{i}, t} N_{i, t}$. For simplification, we assume that $\eta_{i, t}=\Pi_{i, t}$, so that households do not receive dividends after financing new banks.

\section{Parameter Estimates and Model Fit}

In this section, we first present the estimation methodology, the dataset, and the choice of priors. We then comment on the posterior distribution of the structural parameters and the model fit.

\subsection{Estimation Methodology}

We follow the Bayesian approach to estimate the model (see An and Schorfheide, 2007 for an overview). After having cast the model into a stationary form, the non-linear equilibrium equations are solved using first-order approximation methods. Let $\boldsymbol{\theta}$ denote the vector of structural parameters and $\mathbf{v}_{t}$ be the $r$-dimensional vector of model state variables. Thus, the state-space form of the model is given by the state equation $\mathbf{v}_{t}=\mathbb{A}(\boldsymbol{\theta}) \mathbf{v}_{t-1}+\mathbb{B}(\boldsymbol{\theta}) \zeta_{t}$, where $\zeta_{t} \sim$ i.i.d.N $\left(0, \Sigma_{\zeta}\right)$ is the $q$-dimensional vector of innovations to the structural shocks, and $\mathbb{A}(\boldsymbol{\theta})$ and $\mathbb{B}(\boldsymbol{\theta})$ are matrices that depend on the model's parameters $\boldsymbol{\theta}$. The measurement equation is given by $\mathbf{x}_{t}=\mathbb{C}(\boldsymbol{\theta})+\mathbb{D} \mathbf{v}_{t}+\mathbb{E} \mathbf{e}_{t}$, where $\mathbf{x}_{t}$ is an $n$-dimensional vector of observable variables, $\mathbb{D}$ and $\mathbb{E}$ are selection matrices, $\mathbb{C}(\boldsymbol{\theta})$ is a vector that depends on structural parameters, and $\mathbf{e}_{t}$ is a vector of measurement errors.

The Kalman filter is then used to evaluate the likelihood of the observed variables and to form the posterior distribution of the structural parameters by combining the likelihood function with a joint density characterizing some prior beliefs. Given the specification of the model, the posterior distribution cannot be recovered analytically but can be evaluated numerically using a Markov Chain Monte Carlo sampling approach. Specifically, we rely on the 
Metropolis-Hastings algorithm to obtain two chains of 500,000 random draws from the posterior distribution of the parameters.

\subsection{Data}

We use quarterly euro area data covering the period from 1985:Q1 to 2007:Q4. The reason for ending in 2007 is to avoid a bias in the parameter estimates due to the effective lower bound and negative rate episode in the aftermath of the financial crisis and to keep the normal situation as a benchmark. The data are extracted from the Area-Wide Model database compiled by Fagan et al. (2005) and the ECB Statistical Data Warehouse, except hours worked, the working age population, and the real market value of corporate firms. Output growth $\Delta \log Y_{t}$ is obtained as the first difference of the logarithm of real GDP (YER), consumption growth $\Delta \log C_{t}$ is the first difference of the logarithm of real consumption expenditures (PCR), and investment growth $\Delta \log I_{t}$ is the first difference of the logarithm of real gross investment (ITR). Real variables are divided by the working age population extracted from the OECD Economic Outlook. Inflation $\pi_{t}=\Delta \log P_{t}$ is measured by the first difference of the logarithm of the GDP deflator (YED), and real wage growth $\Delta \log \left(W_{t} / P_{t}\right)$ is the first difference of the logarithm of the nominal wage (WRN) divided by the GDP deflator. The short-term nominal interest rate $R_{t}$ is a 3-month Euribor rate (STN). Hours worked $\log L_{t}$ are available for the euro area only from 1995 onward. For the period before 1995, the series is completed with the weighted (by country size) average of the data for Germany, France, and Italy, using the approach of Ohanian and Raffo (2012). Deposits $\log D_{t}$ are proxied using the logarithm of the M1 aggregate, which includes currency in circulation and overnight deposits that can immediately be converted into currency or used for cashless payments. The market value of corporate firms is obtained as the $\log$ arithm of the Stoxx Europe 600 index $\log S_{t}$, which is available from 1986:Q4 and backcasted using the MSCI Europe index (see Christiano et al., 2010). Finally, we remove sample means separately in order to focus on the model implications at business cycle frequency.

The vector of observable variables is then

$$
\mathbf{x}_{t}=100 \times\left[\Delta \log Y_{t}, \Delta \log C_{t}, \Delta \log I_{t}, \Delta \log \left(W_{t} / P_{t}\right), \log L_{t}, \log D_{t}, \log S_{t}, \pi_{t}, R_{t}\right]
$$

Note that $\zeta_{t}$ includes the innovations of nine structural shocks that are defined in detail in Appendix A.6. In addition, since the Stoxx Europe 600 index is only a crude proxy of the market value of corporate firms, $\mathbf{e}_{t}$ includes a measurement error associated with this variable. 


\subsection{Priors and Posteriors}

The set of model parameters is split into two subsets. The first contains parameters calibrated prior to estimation. These parameter values are reported in Table 1. We set the mean (gross) growth rate of the unit root technology shock $\mu_{z}$ to 1.0049 in order to ensure that the model steady state is consistent with the mean growth rate of real per capita GDP in the sample period (1985Q1-2007Q4). In the same way, the steady-state (gross) inflation rate $\pi$ and (gross) short-term rate $R$ are fixed at 1.0074 and 1.0153 , respectively. In using the steady-state relation $\beta=\left(\mu_{z} \pi\right) / R$, we deduce a value of 0.9971 for the discount rate $\beta$. The inverse of the Frisch elasticity of labor supply $v$ is fixed at 2. The capital share $\alpha$ in the Cobb-Douglas production function is set to 0.33 to match the average capital share in net (of fixed costs) output (McAdam and Willman, 2013). The steady-state price and wage markups $\varepsilon_{p}$ and $\varepsilon_{w}$ are set to 1.20 and 1.35, respectively (Everaert and Schule, 2008). Following the recent analysis of ECB (2016), we calibrate the depreciation rate $\delta$ to $1.4 \%$, which corresponds to an average lifetime of the capital stock of approximately 18 years. Tax rates on consumption, labor income, and capital income are computed from implicit tax rates constructed by Eurostat. Using accounting data, we set the ratios of government expenditure to GDP and government debt to GDP at $20 \%$ and $75 \%$, respectively.

Table 1: Calibrated parameters (Time unit of model: quarterly)

\begin{tabular}{lc}
\hline \hline Growth rate of the economy, $\mu_{z}$ & 1.0049 \\
Steady-state inflation rate, $\pi$ & 1.0074 \\
Discount rate, $\beta$ & 0.9971 \\
Curvature on disutility of labor, $v$ & 2.00 \\
Capital share in the production function, $\alpha$ & 0.33 \\
Steady-state price markup, $\varepsilon_{p}$ & 1.20 \\
Steady-state wage markup, $\varepsilon_{w}$ & 1.35 \\
Depreciation rate of capital, $\delta$ & 0.014 \\
Tax rate on consumption, $\tau_{c}$ & 0.19 \\
Tax rate on labor income, $\tau_{n}$ & 0.38 \\
Tax rate on capital income, $\tau_{k}$ & 0.25 \\
Ratio of steady-state government spending to GDP, $g / y$ & 0.20 \\
Ratio of steady-state debt to GDP, $b / y$ & 0.75 \\
Cost of a fire sale, $\phi$ & 0.10 \\
Liquidation cost, $\zeta$ & 0.50 \\
Steady-state risk shock volatility, $\sigma_{s}$ & 0.025 \\
Margin rate, $\mathrm{h}$ & 0.40 \\
Capital ratio, $\vartheta$ & 0.08 \\
\hline
\end{tabular}

Regarding the banking sector, two key parameters, namely, the cost of a fire sale $(\phi)$ and the liquidation cost $(\tilde{\xi})$, are calibrated. The cost of a fire sale is dependent largely on the urgency of the sale. We assume a value of $10 \%$, which is in the range of values uncovered by the 
financial literature, for instance, Coval and Stafford (2007), Shleifer and Vishny (2011), Duarte and Eisenbach (2013), and Caballero and Simsek (2013). We investigate the impact of changes in the cost of a fire sale between 3\% and 30\%.

Estimates of the liquidation cost are very rare. Using data from Chapter 11 proceedings, Gilson (1997) measures the liquidation cost as the going concern value of the firm minus its liquidation value divided by its going concern value. He obtains an estimate of the liquidation cost of approximately 45\%. In addition, Acharya et al. (2007) find that the recovery rates are lower when the industry of the defaulted firms is in distress. They show that this additional loss is due mainly to fire sales. On average, their estimate of the recovery price at emergence is approximately $51 \%$, indicating a liquidation cost of approximately $49 \%$. We assume a benchmark value of $\xi=50 \%$ and investigate the impact on the model of varying $\xi$ between $10 \%$ and $65 \%$. We also calibrate the steady-state cross-sectional dispersion of securities returns. This value cannot be directly calibrated from the volatility of stock markets. Indeed, the risk shock is a cross-sectional dispersion, not a time-series variance. In addition, it measures the crosssection of firm assets, not the cross-section of firm equity. Finally, all firms - not just listed companies - should be considered in the measure of dispersion. We assume a steady-state value equal to $\sigma_{s}=2.5 \%$ per quarter.

The steady-state value of the margin rate is chosen to approximately match the merchant bank leverage. Because there is no direct measure of merchant banks' leverage available in ECB data, we determine $h$ to match the average leverage of other financial intermediaries (excluding monetary financial institutions), which is equal to 2.7 over the sample. The resulting value ( $\mathrm{h}=40 \%$ ) is slightly larger than the margin rates commonly used on the interbank or repo markets for equity securities. We investigate alternative calibrations from $25 \%$ to $60 \%$. Finally, we calibrate the regulatory capital ratio, which is defined as the ratio of bank capital to its risk-weighted assets, equal to $\vartheta=8 \%$, which corresponds to the minimum capital requirements imposed by Basel II.

The remaining 29 parameters are estimated. The prior distribution, mean, and standard deviation are summarized in columns I to III of Table 2. Our priors are in line with the literature, especially with Smets and Wouters (2007), Sahuc and Smets (2008), and Justiniano et al. (2010). The estimation results are displayed in columns IV and V, where the posterior mean and the $90 \%$ confidence interval are reported. All estimated values are consistent with the bulk of contributions in the medium-scale DSGE literature. For instance, our estimate of the habit persistence parameter $\gamma$ is equal to 0.71 . The probability that firms (resp., households) are not allowed to re-optimize their price (resp., wage) is $\theta_{p}=0.73$ (resp., $\theta_{w}=0.71$ ), implying an 
average duration of price and wage contracts of less than one year. These figures are consistent with the results reported in the survey conducted by Druant et al. (2012). Monetary policy parameters $\left(\varphi_{r}, \varphi_{\pi}, \varphi_{y}\right)=(0.76,1.89,0.28)$ indicate that the systematic component of monetary policy displays gradualism with a strong weight on inflation. Our estimates of financial adjustment costs $\left(\psi_{m}\right.$ and $\left.\psi_{d}\right)$ indicate that they are indeed economically significant. As expected, rebalancing the risky portfolio of the merchant bank has a higher cost than rebalancing the portfolio of the deposit bank. Although they do not play an important role in the whole dynamic of the model, they affect the model's short-term response to shocks.

Table 2: Prior densities and posterior estimates

\begin{tabular}{|c|c|c|c|c|c|}
\hline \multirow{3}{*}{ Parameter } & \multirow{2}{*}{\multicolumn{3}{|c|}{ Prior }} & IV & $\mathrm{V}$ \\
\hline & & & & \multicolumn{2}{|c|}{ Posterior } \\
\hline & Distribution & Mean & Std. dev. & Mean & $90 \% \mathrm{CI}$ \\
\hline \multicolumn{6}{|l|}{ Structural parameters } \\
\hline $\begin{array}{l}\text { Habit in consumption, } \gamma \\
\text { Calvo price, } \theta_{p} \\
\text { Calvo wage, } \theta_{w} \\
\text { Price indexation, } \gamma_{p} \\
\text { Wage indexation, } \gamma_{w} \\
\text { Capital utilization cost, } \eta_{u} \\
\text { Investment adjustment cost, } \eta_{k} \\
\text { Monetary policy-smoothing, } \varphi_{r} \\
\text { Monetary policy-inflation, } \varphi_{\pi} \\
\text { Monetary policy-output growth, } \varphi_{y} \\
\text { Merchant bank adjustment cost, } \psi_{m} \\
\text { Deposit bank adjustment cost, } \psi_{d}\end{array}$ & $\begin{array}{l}\text { Beta } \\
\text { Beta } \\
\text { Beta } \\
\text { Beta } \\
\text { Beta } \\
\text { Gamma } \\
\text { Gamma } \\
\text { Beta } \\
\text { Gamma } \\
\text { Gamma } \\
\text { Normal } \\
\text { Normal }\end{array}$ & $\begin{array}{l}0.50 \\
0.75 \\
0.75 \\
0.50 \\
0.50 \\
5.00 \\
4.00 \\
0.85 \\
2.00 \\
0.125 \\
1000 \\
5.00\end{array}$ & $\begin{array}{l}0.10 \\
0.10 \\
0.10 \\
0.15 \\
0.15 \\
1.00 \\
1.00 \\
0.10 \\
0.10 \\
0.05 \\
100 \\
0.50\end{array}$ & $\begin{array}{l}0.71 \\
0.73 \\
0.71 \\
0.23 \\
0.21 \\
5.54 \\
3.61 \\
0.76 \\
1.89 \\
0.28 \\
1068 \\
5.01\end{array}$ & $\begin{array}{l}{[0.52,0.87]} \\
{[0.66,0.82]} \\
{[0.65,0.77]} \\
{[0.12,0.30]} \\
{[0.13,0.32]} \\
{[4.29,6.67]} \\
{[2.41,4.67]} \\
{[0.70,0.81]} \\
{[1.83,1.97]} \\
{[0.19,0.36]} \\
{[955,1147]} \\
{[4.11,5.99]}\end{array}$ \\
\hline \multicolumn{6}{|l|}{ Persistence parameters } \\
\hline $\begin{array}{l}\text { Preference shock, } \rho_{b} \\
\text { Investment shock, } \rho_{i} \\
\text { Government shock, } \rho_{g} \\
\text { Price markup shock, } \rho_{p} \\
\text { Wage markup shock, } \rho_{w} \\
\text { Transitory technology shock, } \rho_{a} \\
\text { Risk shock, } \rho_{\sigma}\end{array}$ & $\begin{array}{l}\text { Beta } \\
\text { Beta } \\
\text { Beta } \\
\text { Beta } \\
\text { Beta } \\
\text { Beta } \\
\text { Beta }\end{array}$ & $\begin{array}{l}0.50 \\
0.50 \\
0.50 \\
0.50 \\
0.50 \\
0.50 \\
0.50\end{array}$ & $\begin{array}{l}0.20 \\
0.20 \\
0.20 \\
0.20 \\
0.20 \\
0.20 \\
0.20\end{array}$ & $\begin{array}{l}0.58 \\
0.95 \\
0.86 \\
0.57 \\
0.15 \\
0.93 \\
0.97\end{array}$ & $\begin{array}{l}{[0.21,0.88]} \\
{[0.92,0.97]} \\
{[0.83,0.89]} \\
{[0.34,0.80]} \\
{[0.04,0.28]} \\
{[0.87,0.98]} \\
{[0.96,0.99]}\end{array}$ \\
\hline \multicolumn{6}{|l|}{ Volatility parameters } \\
\hline $\begin{array}{l}\text { Preference shock, } \sigma_{b} \\
\text { Investment shock, } \sigma_{i} \\
\text { Government shock, } \sigma_{g} \\
\text { Price markup shock, } \sigma_{p} \\
\text { Wage markup shock, } \sigma_{w} \\
\text { Persistent technology shock, } \sigma_{z} \\
\text { Transitory technology shock, } \sigma_{a} \\
\text { Risk shock, } \sigma_{\sigma} \\
\text { Monetary policy shock, } \sigma_{r} \\
\text { Measurement error, } \sigma_{n}\end{array}$ & $\begin{array}{l}\text { Inv. Gamma } \\
\text { Inv. Gamma } \\
\text { Inv. Gamma } \\
\text { Inv. Gamma } \\
\text { Inv. Gamma } \\
\text { Inv. Gamma } \\
\text { Inv. Gamma } \\
\text { Inv. Gamma } \\
\text { Inv. Gamma } \\
\text { Inv. Gamma }\end{array}$ & $\begin{array}{l}0.01 \\
0.01 \\
0.01 \\
0.01 \\
0.01 \\
0.01 \\
0.01 \\
0.01 \\
0.01 \\
0.01\end{array}$ & $\begin{array}{l}0.015 \\
0.015 \\
0.015 \\
0.015 \\
0.015 \\
0.015 \\
0.015 \\
0.015 \\
0.015 \\
0.015 \\
\end{array}$ & $\begin{array}{l}0.051 \\
0.009 \\
0.004 \\
0.010 \\
0.116 \\
0.007 \\
0.004 \\
0.209 \\
0.002 \\
0.080 \\
\end{array}$ & $\begin{array}{l}{[0.025,0.083]} \\
{[0.007,0.013]} \\
{[0.003,0.004]} \\
{[0.008,0.013]} \\
{[0.100,0.135]} \\
{[0.005,0.008]} \\
{[0.003,0.005]} \\
{[0.172,0.239]} \\
{[0.001,0.002]} \\
{[0.074,0.087]}\end{array}$ \\
\hline
\end{tabular}

Note: This table reports the prior distribution, the mean and the 90 percent confidence interval of the estimated posterior distribution of the structural parameters. 
The most persistent shock is the risk shock, with an autoregressive parameter estimate of 0.97, similar to the value obtained by Christiano et al. (2014). The next-largest autoregressive parameters of shocks are those pertaining to investment and transitory technology shocks, with estimates equal to 0.95 and 0.93 , respectively.

\subsection{Model Evaluation}

To assess the dynamic properties of the model, we evaluate the following key macroeconomic and financial variables: (i) the forecast error variance decomposition at business cycle frequency and (ii) the impulse response functions to various shocks. Both analyses are useful in assessing how shocks to economic variables reverberate through the system.

The variance decomposition is presented in Table 3. Unexpected business cycle output fluctuations are explained mainly by investment and technology shocks. Preference shocks are the major source for the forecast error in consumption, followed by risk shocks. More than $60 \%$ of investment fluctuations are explained by investment and risk shocks. Monetary policy shocks also contribute to $10 \%$ of investment fluctuations. Price and wage markup shocks are the major source of unexpected fluctuations in the inflation process (29\% overall), followed by preference and investment shocks. Both demand shocks are also responsible for $64 \%$ of the unexpected interest rate fluctuations. As highlighted by Christiano et al. (2014), the risk shock is an important contributor to consumption and investment fluctuations, but it does not contribute as much to inflation and interest rate fluctuations.

Table 3: Variance decomposition at business cycle frequency (percent)

\begin{tabular}{lccccccc}
\hline \hline Shock: & $\begin{array}{c}\text { I } \\
\text { Techno- } \\
\text { logy } \\
\left(\sigma_{z}, \sigma_{a}\right)\end{array}$ & $\begin{array}{c}\text { II } \\
\text { Prefe- } \\
\text { rence } \\
\left(\sigma_{b}\right)\end{array}$ & $\begin{array}{c}\text { III } \\
\text { Invest- } \\
\text { ment } \\
\left(\sigma_{i}\right)\end{array}$ & $\begin{array}{c}\text { IV } \\
\text { Mark } \\
\text { ups } \\
\left(\sigma_{p}, \sigma_{w}\right)\end{array}$ & $\begin{array}{c}\text { V } \\
\text { Govern- } \\
\text { ment } \\
\left(\sigma_{g}\right)\end{array}$ & $\begin{array}{c}\text { VI } \\
\text { Monet. } \\
\text { policy } \\
\left(\sigma_{r}\right)\end{array}$ & $\begin{array}{c}\text { VII } \\
\text { Risk }\end{array}$ \\
Variable: & 22.4 & 17.0 & 30.9 & 8.4 & 3.2 & 5.4 & 12.8 \\
Output & 7.7 & 31.1 & 15.9 & 7.1 & 8.9 & 8.5 & 20.8 \\
Consumption & 5.4 & 4.1 & 36.8 & 8.4 & 7.6 & 10.0 & 27.8 \\
Investment & 5.8 & 39.9 & 19.4 & 14.3 & 4.3 & 6.0 & 10.3 \\
Hours worked & 11.5 & 23.4 & 18.5 & 28.9 & 3.5 & 7.2 & 7.1 \\
Inflation rate & 9.6 & 25.0 & 37.8 & 7.7 & 5.7 & 5.2 & 9.1 \\
Risk-free interest rate & 32.2 & 6.5 & 25.5 & 8.1 & 4.0 & 6.9 & 16.8 \\
Securities & 30.9 & 1.4 & 14.0 & 12.5 & 21.3 & 14.3 & 5.7 \\
Deposits & 17.6 & 0.2 & 3.6 & 17.4 & 29.7 & 22.9 & 8.4 \\
Merchant bank leverage & & & & & & & \\
\hline
\end{tabular}

Note: For each variable indicated in the first column, variance decomposition is generated by the model evaluated at the mean of the posterior distribution.

The variance decomposition of the financial variables also provides several important insights. Approximately $60 \%$ of the business cycle variance in the market value of securities is 
explained by technology and investment shocks and $17 \%$ by risk shocks. While $45 \%$ of the business cycle variance in deposits is also explained by technology and investment shocks, government spending shocks contribute to $21 \%$. Fluctuations in the merchant bank's leverage are driven mostly by government spending and monetary policy shocks.

Together, these results illustrate that the investment shock is the main driver of fluctuations in the production side (output, investment, securities, and interest rate), consistent with Justiniano et al. (2010). In addition, the risk shock explains a large portion of the variance in macroeconomic and financial variables, especially through the financing of capital equipment.

We now discuss the impulse response functions of the key macroeconomic and financial variables to several common macroeconomic shocks. Line 1 of Figure 3 displays key variables' response to a transitory technology shock. ${ }^{13}$ Because this shock is highly persistent, we observe long-lasting responses from all variables. Following a one-standard-deviation positive shock, output is mechanically boosted through the production function. Because the demand and price of capital increase, firms issue more securities to finance their new physical capital. In parallel, deposits increase because the real interest rate rises and consumption increases less than household revenues at impact. Because the value of securities increases, the merchant bank can rely more on collateralized debt financing than on equity financing. Therefore, the merchant bank leverage strongly increases, confirming its procyclical dynamics. As the merchant bank takes on more leverage, the deposit bank raises more equity and increases its cash buffer to reduce its own risks.

Line 2 of Figure 3 shows that a positive shock to investment efficiency results in a large increase in investment and a decrease in consumption, with an overall positive impact on total output. A similar crowding-out effect is observed by Smets and Wouters (2003). To partially compensate for the drop in consumption, the household reduces its deposits. In addition, the price of existing capital lowers, which results in a decrease in the value of firm securities in the short term. The merchant bank is forced to reduce its debt financing and increase its equity financing, which decreases its leverage. The deposit bank reduces its equity financing and its cash buffer because the merchant bank is relatively less risky. In the long term, as capital is replaced by the new technology, the value of the firm's equipment increases, which allows the merchant bank to rely more heavily on leverage to finance its investment in firm securities.

\footnotetext{
${ }^{13}$ In the figures displaying impulse responses, we do not show the impact of a shock on the deposit bank's leverage, although this is variable is key to driving risks in the financial system because in equilibrium, the regulatory capital constraint is binding and the deposit bank keeps its leverage fixed at its maximum value. In addition, banks' probability of default and the SEL are not affected by small shocks because such shocks are insufficient to meeting the default thresholds. As we will see in Section 4, in a crisis scenario, deposit bank leverage and default are substantially affected by large shocks.
} 

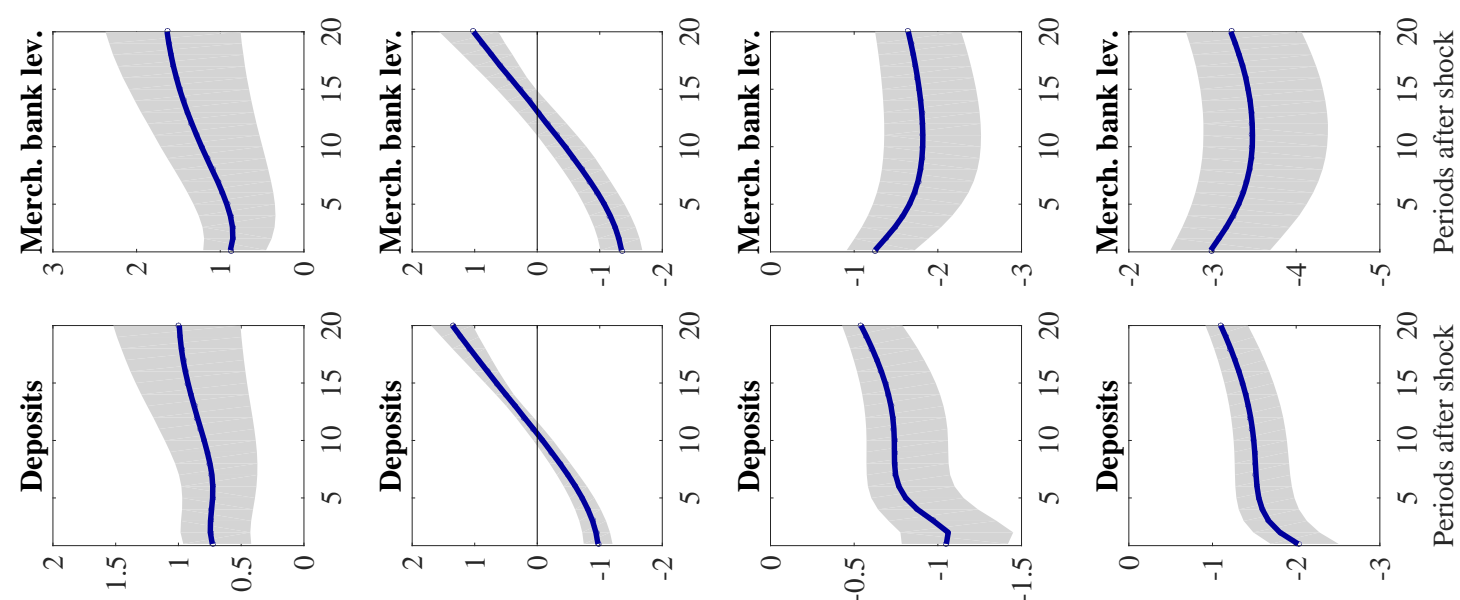

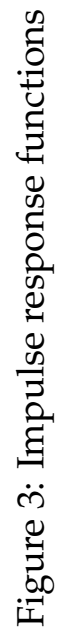
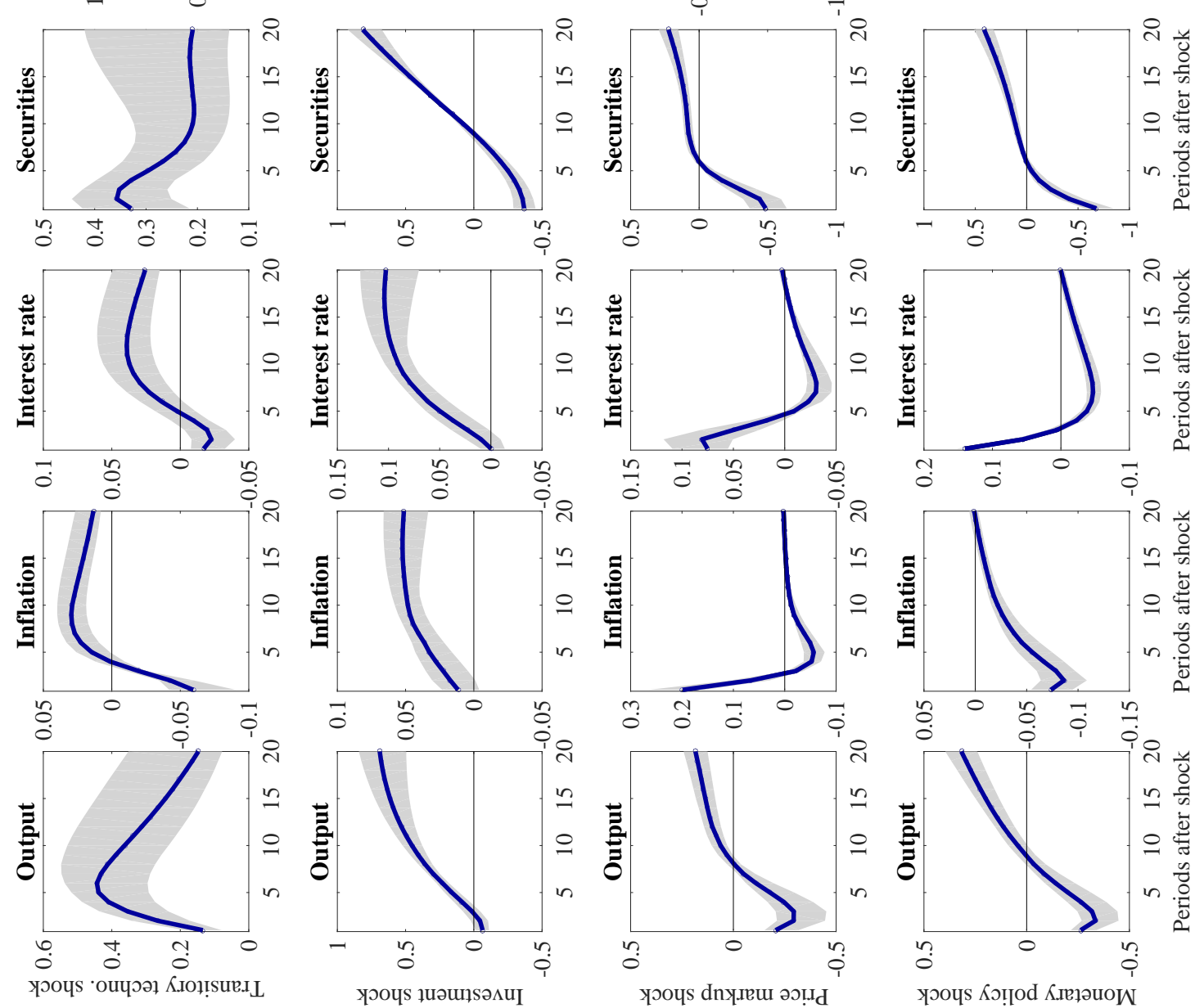
Line 3 of Figure 3 illustrates the impulse responses to a positive price markup shock. Following the increase in inflation, the central bank raises its short-term policy rate, which in turn reduces output. Both the demand and price of capital decrease so that the value of firm securities decreases. The decline in real wages also implies a drop in consumption, which is partly compensated by the decrease in household deposits. Given the decrease in the value of its collateral, the merchant bank is forced to reduce its debt and relies more heavily on equity to finance the firm's capital demand. Consequently, the bank's leverage substantially decreases. Because the merchant bank is less risky, the deposit bank reduces its cash buffer to partly compensate for the decrease in deposits.

Finally, Line 4 of Figure 3 reports the responses to a monetary policy shock. A positive shock has the usual negative impact on output and inflation. Deposits substantially decrease to compensate for the drop in household revenues. The effect on the financial sector is also clear: as the value of securities suffers from monetary tightening, the merchant bank must delever and rely more strongly on equity to finance the firm's investment. Therefore, its leverage significantly decreases and the deposit bank can reduce its cash buffer.

In summary, the model produces the expected dynamics of the key macroeconomic and financial variables, as in Smets and Wouters (2003), Angeloni and Faia (2013), Christiano et al. (2014), and Nuño and Thomas (2017), among others. In particular, the model generates procyclical dynamics of the merchant bank's leverage. Over time, the increase in the value of the securities allows the merchant bank to increase its debt financing, which results in higher leverage. The deposit bank increases its cash buffer to reduce its own exposure to the merchant bank's risk of default. Because its capital ratio constraint is binding, it issues more equity to finance its cash buffer so that the overall equity financing is not altered.

\section{Stressed Expected Loss}

The capital shortfall, which is defined in Equation (2), measures the expected loss on deposits as a result of the deposit bank's default. The deposit insurance premium is an "unstressed" measure of risk because it is not associated with an economic crisis. Acharya et al. (2012) and Brownlees and Engle (2017) define systemic risk as a financial firm's propensity to be undercapitalized when the overall financial system is undercapitalized. In our model, this definition corresponds to a "stressed" version of the expected loss, i.e., it is associated with an adverse scenario. 


\subsection{Measuring Stressed Expected Loss}

To measure SEL in the model, we proceed as follows. The economy is in equilibrium at the end of period $t-1$, and interest rates $\left(R_{t}, R_{d, t}\right.$ and $\left.R_{b, t}\right)$ are determined for the next period. At the beginning of period $t$, banks optimally determine their cash buffer $\left(a_{m, t}^{*}\right.$ and $\left.a_{d, t}^{*}\right)$. The various quantities $\left(S_{t}, B_{t}, D_{t}, M_{m, t}\right.$, and $\left.M_{d, t}\right)$ and thresholds $\left(\bar{R}_{s, t}, \underline{R}_{s, t}\right.$, and $\left.\underline{R}_{s d, t}\right)$ are also determined. Then, in period $t$, a crisis occurs. Some large shocks affect the production and financial sectors of the economy and imply a shift in the distribution of the firm's return on investment, $\tilde{R}_{s, t}$. We denote by $\mu_{s}^{(\text {crisis })}$ the stressed expected return on securities $\left(\mu_{s}^{(\text {crisis })}<\mu_{s, t}\right)$ and by $\sigma_{s}^{(\text {crisis })}$ the stressed cross-sectional dispersion $\left(\sigma_{s}^{(\text {crisis })}>\sigma_{s, t}\right)$. Therefore, the probability that $\tilde{R}_{s, t}$ belongs to a given interval is computed with the stressed distribution $N\left(\mu_{s}^{(c r i s i s)}, \sigma_{s}^{(c r i s i s) 2}\right)$. The stressed expected loss on deposits, denoted by $S E L_{t}=C S_{d, t}^{(\text {crisis })}$, is derived from Equation (2) as follows:

$$
S E L_{t}=\left[R_{d, t} D_{t}-\mu_{s, t}^{(d e f d \mid c r i s i s)}(1-\xi) S_{t}-R_{t}\left(M_{m, t}+M_{d, t}\right)\right] \Pi_{t}^{(d e f d \mid c r i s i s)},
$$

where $\mu_{s, t}^{(\text {defd } \mid \text { crisis })}=\mathrm{E}_{t}\left[\tilde{R}_{s, t} \mid \tilde{R}_{s, t} \leq \underline{R}_{s d, t} ;\right.$ crisis $]$ is the expected return on securities if the deposit bank defaults during the crisis and $\Pi_{t}^{(\text {defd } d \mid c r i s i s)}=\operatorname{Pr}\left[\tilde{R}_{s, t} \leq \underline{R}_{s d, t} \mid\right.$ crisis $]$ is the probability of a deposit bank default during the crisis.

Several elements contribute to SEL. First, SEL is the difference between the book value of deposits and the expected market value of the assets under stress. The book value of deposits corresponds to an unstressed expected value because the value that must be repaid is not affected by the crisis. Second, the expected value of the assets held by the deposit bank under stress has two components: the expected value of the loan and the value of cash. The former is subject to a loss during the crisis, whereas the latter is not affected. As indicated by the term in squared brackets in Equation (B.5), the expected return of the loan under stress depends on the assets left by the defaulting merchant bank: (1) the market value of the securities held by the merchant bank, which incurs a loss because of the crisis $\left(\mu_{s, t}^{(d e f d \mid c r i s i s)}\right)$ and is further reduced by the liquidation cost; and (2) the value of the cash held by the merchant bank.

A simple way to rewrite SEL is

$$
S E L_{t}=\mathrm{E}_{t}\left[D_{t+1}^{(\text {guar })}-\text { Assets }_{d, t+1}^{(\text {defd } \mid \text { crisis })}\right] \Pi_{t}^{(\text {defd|crisis })}
$$

where $D_{t+1}^{\text {(guar) }}=R_{d, t} D_{t}$ is the book value of the deposits guaranteed by the deposit insurance (including interest payments) and Assets $s_{d, t+1}^{(\text {defd } \text { crisis) }}$ is the marked-to-market value of the deposit bank's assets if it defaults during the crisis. 


\subsection{Simulating a Crisis}

Standard impulse response analysis obtained from a first-order approximation of the model cannot be used to analyze the impact of an adverse scenario. This is the case because the default thresholds are not affected when small shocks are considered, so the probability of default of merchant and deposit banks are typically equal to 0 and capital shortfall remains negligible. We measure SEL in a crisis using deterministic simulations of the non-linear version of the model under large shocks. Our strategy is similar to that of Brunnermeier and Sannikov (2014), who show that due to nonlinearities in their model, large shocks affect the economy differently than small shocks do. The nonlinearities in our model (essentially the fire sale and default thresholds) play a fundamental role in the development of a crisis, whereas they are neglected in standard impulse response analysis.

We consider a combination of a (negative) shock to the efficiency of the investment in capital equipment $\left(\zeta_{i, t}\right)$ and a (positive) shock to the cross-sectional dispersion of firm's securities returns $\left(\zeta_{\sigma, t}\right){ }^{14}$ The investment shock is calibrated to reproduce the drop in investment that we observe during the subprime crisis (-15.2\% between the end of 2007 and 2010). The shock to the cross-sectional dispersion of securities returns is calibrated to reproduce the increase in deposit bank leverage that we observe in the data. European monetary financial institutions raised their leverage by 3.6 (from 7.9 to 11.5 between 2007 and 2010 on average). ${ }^{15}$

\subsection{Impact of a Crisis on Macroeconomic Variables}

As expected, the crisis scenario generates a drop in macroeconomic quantities. In Table 4, we display the observed variations in macroeconomic variables (between the beginning of 2008 and the minimum value in the next two years) and the simulated variations generated by our crisis scenario (the percentage difference between the steady-state value and the minimum value in the next two years). The decrease in investment by 15.2\% from 2008:Q1 to 2010:Q1 is used to calibrate the investment shock. During the subprime crisis, private consumption and GDP declined by 1.7\% and 5.7\% compared to 2008:Q1 (with minimums in 2009:Q4 and 2009:Q2, respectively). In our simulation, the decreases in consumption and output are equal to $2.9 \%$ and $5 \%$, respectively.

Furthermore, the annualized inflation rate and the risk-free interest rate substantially decreased during the subprime crisis, by $1.8 \%$ and $3.8 \%$, respectively. Simulated series decreased

\footnotetext{
${ }^{14}$ Other crisis scenarios could be considered, such as a technology shock instead of an investment shock.

${ }^{15}$ Technically, the innovation $\zeta_{i, t}$ is equal to -0.31 , which corresponds to a shock to investment efficiency equal to $\varepsilon_{i, t}=-0.27$ such that investment decreases by $15.2 \%$. The innovation $\zeta_{\sigma, t}$ is equal to 2.3 , which corresponds to a cross-sectional dispersion of securities returns equal to $\sigma_{s, t}=0.25$, or 10 times its steady-state value.
} 
Table 4: Macroeconomic effects of a crisis (percent)

\begin{tabular}{lcc}
\hline \hline & I & II \\
& Data & Simulation \\
\hline Output & -5.72 & -5.03 \\
Consumption & -1.67 & -2.88 \\
Investment & -15.18 & -15.20 \\
Hours worked & -4.78 & -5.46 \\
Inflation rate & -1.81 & -2.78 \\
Risk-free interest rate & -3.82 & -3.24 \\
\hline
\end{tabular}

Note: The figures represent the percentage difference between the value at the beginning of 2008 (for the data) or at the steady state (for the simulation) and the minimum value in the next two years for each variable.

by $2.8 \%$ and $3.2 \%$, respectively. We note that the real interest rate is also declined in the scenario, although less than the decline observed with actual data. This difference in nominal variables can be explained by the monetary policy implemented by the ECB in the aftermath of the crisis. Indeed, to address tight financing conditions at long maturities, the ECB changed the maturity structure of its liquidity-providing operations by providing collateralized loans over longer-than-usual time horizons (3, 6, and 12-month operations) in 2008 and 2009. ${ }^{16}$ As an example, the first 12-month operations were allotted in June 2009 at an amount of 442 billion euros. Cahn et al. (2017) show that such liquidity injections have helped reduce the drop in consumption and the GDP deflator in the aftermath of the crisis.

It is noteworthy that according to ECB data, the decrease in the value of securities issued by non-financial corporations (debt and shares) equaled 21\% in real terms between 2008:Q1 and 2009:Q1. In our simulation experiment, the drop in securities was also equal to $21 \%$, whereas the simulation exercise was not calibrated to match this number. This result suggests that the magnitude of our experiment is similar to the magnitude of the subprime crisis.

\subsection{Impact of a Crisis on Banks' Balance Sheet}

The risk shock, i.e., the shock to the cross-sectional dispersion of securities returns, is the main driver of banks' balance sheet dynamics. As the cross-sectional dispersion of the shock on the quality of capital increases, the proportion of firms with poor-quality capital increases, and consequently, the proportion of merchant banks with low revenues increases. As Table 5 reports, whereas in normal conditions, $99.9 \%$ of merchant banks do not face any difficulty in

\footnotetext{
${ }^{16}$ In October 2008, the Eurosystem also switched all its refinancing operations to the so-called "fixed rate with full allotment" modality, thereby fully accommodating private banks' demand for central bank liquidity at the central policy rate.
} 
repaying their debt, only $49 \%$ have enough capital in the crisis scenario. Because long-term claims on firm's assets are used as collateral to secure the loan, 25\% of merchant banks must sell some of their assets in a fire sale to reduce their leverage, which reinforces the loss on risky securities. For $26 \%$ of merchant banks, the revenues generated are so low that the banks default.

On average, the value of the securities held by merchant banks decreases by $21 \%$ (exactly the same change as that observed in the subprime crisis), while the value of their cash buffer is reduced by $75 \%$, decreasing their debt. Overall, the value of the assets drops by $26 \%$. The deleveraging process and the default of some merchant banks lead to a large decrease in the value of the loan (by $45 \%$ ) while the equity increases by $8 \%$. Eventually, merchant banks substantially reduce their leverage - from 2.7 to 1.9 in our calibration. This result is consistent with the theoretical and empirical evidence provided by Adrian and Shin (2010, 2014), who find that merchant banks' leverage is procyclical.

In the crisis scenario, deposit banks suffer from this deleveraging and the eventual default of some merchant banks. Given the lower limit the regulator imposes on deposit banks' capital ratio and the holding of a cash buffer, the proportion of deposit banks that default in the crisis is much smaller than the proportion of merchant banks that default - it is equal to $6.2 \%$, meaning that $19.4 \%$ of deposit banks survive despite a default of the merchant banks to which they have lent. In the case of a merchant bank default, the deposit bank liquidates the assets of the merchant bank and receives the proceeds in cash. Therefore, the value of cash held by deposit banks increases on average by $66 \%$. Due to the drop in the value of the total assets (by $25 \%$ ) and the default of some deposit banks, household deposits are reduced on average by $12 \%$ and equity is reduced by $46 \%$. As a consequence, leverage increases substantially (from 9.5 to 13.1). This result is consistent with evidence reported by He and Krishnamurthy $(2012,2014)$, who find that deposit banks' leverage is countercyclical.

Finally, for the deposit banks that default in the crisis, the marked-to-market value of their remaining assets is equal to $33.3 \%$ of GDP, whereas the book value of the deposits (included interests due to households) is equal to $36.1 \%$ of GDP. As a consequence, the capital shortfall of the defaulting deposit banks amounts to $2.8 \%$ of GDP, which is our measure of SEL. It corresponds in our calibration to approximately 250 billion euros, or $8.5 \%$ of the assets of the defaulting banks. We note that the deposit banks' total loss of equity in the crisis is equal to $46 \%$ of their steady-state equity. This number can be compared to the decrease in European banks' market capitalization of approximately 50\% observed between the end of 2007 and the end of 2008. 
Table 5: Financial effects of a crisis

\begin{tabular}{lcc}
\hline \hline & $\begin{array}{c}\text { I } \\
\text { Normal time }\end{array}$ & $\begin{array}{c}\text { II } \\
\text { Crisis }\end{array}$ \\
\hline Merchant bank & & \\
Probability of good time $\left(\operatorname{Pr}\left[\tilde{R}_{s, t}>\bar{R}_{s, t}\right]\right)$ & $99.9 \%$ & $48.9 \%$ \\
Probability of fire sale $\left(\operatorname{Pr}\left[\tilde{R}_{s, t} \in\left[\underline{R}_{s, t}, \bar{R}_{s, t}\right]\right]\right)$ & $0.1 \%$ & $25.5 \%$ \\
Probability of default $\left(\operatorname{Pr}\left[\tilde{R}_{s, t} \leq \underline{R}_{s, t}\right]\right)$ & $0.0 \%$ & $25.6 \%$ \\
Change in Cash & - & $-75.2 \%$ \\
Change in Securities & - & $-20.8 \%$ \\
Change in Loan & - & $-45.4 \%$ \\
Change in Equity & - & $+8 \%$ \\
Leverage & 2.7 & 1.9 \\
\hline Deposit bank & & \\
Probability of normal time $\left(\operatorname{Pr}\left[\tilde{R}_{s, t}>\underline{R}_{s, t}\right]\right)$ & $100 \%$ & $74.4 \%$ \\
Probability of survival $\left(\operatorname{Pr}\left[\tilde{R}_{s, t} \in\left[\underline{R}_{s d, t}, \underline{R}_{s, t}\right]\right]\right)$ & $0.0 \%$ & $19.4 \%$ \\
Probability of default $\left(\operatorname{Pr}\left[\tilde{R}_{s, t} \leq \underline{R}_{s d, t}\right]\right)$ & $0.0 \%$ & $6.2 \%$ \\
Change in Cash & - & $+66.2 \%$ \\
Change in Loan & - & $-45.4 \%$ \\
Change in Deposits & - & $-13.7 \%$ \\
Change in Equity & - & $-45.7 \%$ \\
Leverage & 9.5 & 13.1 \\
SEL (\% of output) & $0.0 \%$ & $2.8 \%$ \\
\hline
\end{tabular}

Note: For probability and leverage values, the figures represent the levels obtained in normal time (steady state) and in crisis. For changes in quantities, the figures represent the percentage difference between the value at the steady state and the minimum value in the next two years for each variable.

\subsection{Sensitivity to Key Parameters}

In this section, we investigate the sensitivity of our findings to certain perturbations, such as the amplitude of the shocks and the calibration of several key parameters.

In our benchmark scenario, the financial crisis is simulated through two shocks: an investment shock, which generates the economic recession, and a risk shock, which drives the financial crisis. As expected, the magnitude of these two shocks affects the banks' probability of default and SEL. If the risk shock is kept fixed, a stronger investment shock has a large impact on both macroeconomic and financial variables (see Figure 4, Line 1). Increasing the magnitude of the (negative) shock from $0 \%$ to $35 \%$ reduces investment and GDP by $30 \%$ and $8 \%$, respectively. A more negative investment shock also results in a decrease in the value of securities held by the merchant banks and an increase in their probability of default, up to $35 \%$. As noted above, the deleveraging of merchant banks is driven by the risk shock. When this shock is fixed, a more severe investment shock results in a loss of equity for these banks, so their leverage slightly increases. Deposit banks' leverage and the probability of default also increase, up to 14 and 11\%, respectively. As a result, SEL increases up to 9\% of GDP. 
The main driver of the financial crisis is the risk shock. As Line 2 of Figure 4 illustrates, the impact of the risk shock on output and investment is limited. In addition, when the investment shock is kept fixed, a threshold effect associated with this shock occurs. When the volatility is below a given value (approximately 10\%), the probability of default and SEL are equal to 0. However, when the cross-sectional dispersion is above this threshold, there is a substantial increase in the risks borne by the banking system. When the cross-sectional dispersion increases from $10 \%$ to $40 \%$, the value of the loan collateral decreases and some merchant banks must sell some of their securities to reduce their leverage (from 2.6 to 1.5). Some of these banks even default, so the value of the interbank loan decreases even more (from 16 to 6). Because deposits only slightly decrease, deposit banks' leverage strongly increases (from 9.5 to 16.5). Therefore, the probability of default increases to $40 \%$ for merchant banks and $20 \%$ for deposit banks, while SEL jumps to 14\% of GDP.

Additionally, two important cost parameters in our model could severely affect SEL, by amplifying the effect of the initial shocks: the cost of a fire sale $(\phi)$, which measures the cost for the merchant banks to delever and sell their risky assets in a market crisis, and the liquidation cost $(\xi)$, which corresponds to the cost for deposit banks to liquidate the risky assets of defaulting merchant banks.

An increase in the cost of a fire sale always raises merchant banks' probability of default because the banks will suffer more in a crisis, regardless of their own decisions (see Figure 4, Line 3). Merchant banks reduce their exposure to risky assets in an attempt to mitigate a higher cost of a fire sale: when $\phi$ increases from 3\% to 30\%, the fraction of equity kept in cash increases and the value of securities decreases so that the overall leverage slightly reduces. For deposit banks, the impact of an increase in $\phi$ is different: even if the merchant banks take less risk to mitigate their higher cost in a fire sale, in a crisis, their deleveraging is not sufficient and their probability of default is much higher (up to 48\%) because of the higher cost of a fire sale. If some merchant banks default, deposit banks will face a liquidation cost, which is held fixed at $\xi=50 \%$. Therefore, deposit banks essentially benefit from merchant banks having less risky assets. In the end, the deposit banks' probability of default decreases from $6.6 \%$ to $3.2 \%$ when $\phi$ increases from $3 \%$ to $30 \%$. Similarly, SEL decreases from $3.1 \%$ to $1.2 \%$ of GDP. 

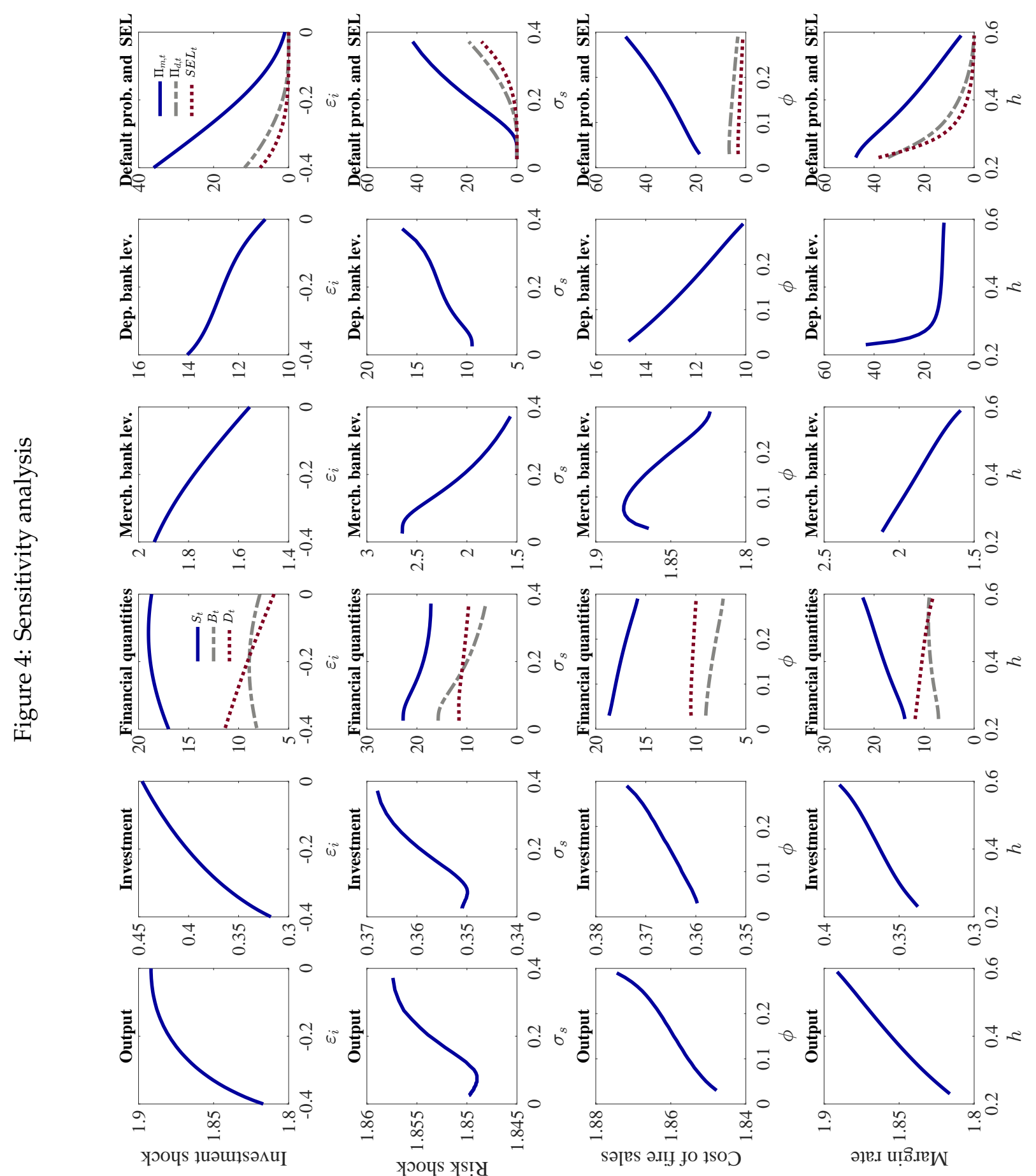
In the case of an increase in the liquidation cost (not reported to save space), the impact on macroeconomic variables is limited: output and investment are barely affected by the change in the value of the parameter. Financial quantities (securities, loans, and deposits) slightly decrease as the liquidation cost increases. When the cost of liquidation increases, deposit banks are less likely to survive in the event of a crisis. For instance, the probability of default increases from $0.6 \%$ to $28 \%$ when $\xi$ increases from $10 \%$ for $65 \%$. Because deposit banks are riskier, their cost of financing increases (due to the insurance premium on deposits), which further increases the deposit banks' probability of default. Similarly, SEL increases from $0.2 \%$ to $19 \%$ of GDP.

Finally, we analyze the effects of the variation in the margin rate (h). The contrasting impacts between normal conditions and the crisis period are obtained. In equilibrium, a lower margin rate results in an increase in bank lending and therefore in a higher GDP. The increase in the merchant banks' leverage is harmless because banks do not default. In contrast, in a crisis, the margin rate drives the level of risk taken by merchant banks (Figure 4, Line 4). Reducing the margin rate from $40 \%$ to $25 \%$ increases the merchant banks' probability of default from $25 \%$ to $46 \%$ and that of the deposit bank from $6.2 \%$ to $29 \%$. The SEL also substantially increased from $2.8 \%$ to $28 \%$ of GDP. It is worth emphasizing that the higher financial risks implied by a lower margin rate also negatively affect macroeconomic variables because deposit banks reduce their risk exposure by lending less to merchant banks, which must reduce their investment in firm's securities. In a crisis, investment and GDP are 5.9\% and 1.8\% lower for a margin rate equal to $25 \%$ than for a margin rate equal to $40 \%$.

\subsection{Macroprudential Analysis}

We now consider a version of the model in which the capital ratio $\vartheta$ is made dependent on the state of the economy through indicators that vary with the economic cycle. This mechanism is described in Alpanda et al. (2014), Clerc et al. (2015), Levine and Lima (2015), Gelain and Ilbas (2017), and Pietrunti (2017), among others. The objective of a countercyclical capital ratio is that the capital ratio increases in good conditions so that it can be used as a buffer in a financial crisis. Business cycle indicators typically include the output and bank credit granted to corporate firms. We also allow the rule to depend on a measure of the capital shortfall borne by the banking system (i.e., $S E L_{t}$ ). 
We have investigated several specifications of the policy rule and retained the following general formulation:

$$
\frac{\vartheta_{t}}{\vartheta}=\left(\frac{Y_{t}}{\mu_{z} Y_{t-1}}\right)^{\beta_{\Delta y}}\left(\frac{S_{t}}{\mu_{z} S_{t-1}}\right)^{\beta_{\Delta S}}\left(\frac{S E L_{t}}{Y_{t}}\right)^{\beta_{S E L}},
$$

where $\vartheta$ is the steady-state capital ratio, $\beta_{\Delta y}, \beta_{\Delta S}$, and $\beta_{S E L}$ denote the sensitivity of the capital ratio to output growth $Y_{t} /\left(\mu_{z} Y_{t-1}\right)$, credit growth $S_{t} /\left(\mu_{z} S_{t-1}\right)$, and SEL, respectively. In principle, this relation can produce a procyclical or a countercyclical capital requirement depending on the signs of the $\beta_{\Delta y}$ and $\beta_{\Delta S}$ parameters. When $\beta_{\Delta y}$ and $\beta_{\Delta S}$ are positive, this relation can be interpreted as a countercyclical capital buffer, as prescribed in the Basel III regulatory framework. Our goal is to compare alternative macroprudential rules in terms of welfare. Welfare is measured as:

$$
\mathscr{W}_{t}=\mathrm{E}_{t}\left[\sum_{s=0}^{\infty} \beta^{s} \mathscr{U}_{t+s}\right],
$$

where $\mathscr{U}_{t}$ is the household period utility function (see Equation (A.1) of Appendix A). We proceed as follows. First, we compare standard macroprudential rules to the case of a constant capital requirement ratio equal to $8 \%$. Second, we compare these standard rules to rules that also include SEL. In each case, the parameters associated with the indicators are obtained as a result of welfare maximization.

Table 6 reports the effect of a crisis under different optimized macroprudential rules. Specifically, it reports the change in the main macroeconomic variables relative to their steady-state level and the level of some of the financial variables. In the case of a constant capital ratio (column I), as assumed in Sections 4.3 and 4.4, in a crisis, the expected loss of output, consumption, and investment is equal to $5 \%, 2.9 \%$, and $15.2 \%$, respectively, relative to the steady state. Given the loss in the value of the assets, merchant banks severely delever (from 2.7 to 1.9), while the loss in the equity of deposit banks results in a substantial increase of their leverage (from 9.5 to 13.3 ). The probability of default jumps to $25.6 \%$ and $6.2 \%$ for merchant banks and deposit banks, respectively. SEL is equal to $2.8 \%$ of GDP in the crisis.

We now assume a rule in which the business cycle indicator is output growth (column II). This rule is not very effective: welfare and consumption are only slightly increased compared to the case with a constant capital ratio. The loss in consumption is $2.7 \%$ instead of $2.8 \%$. In addition, this rule implies a more fragile banking system. As merchant banks incur large losses on their assets and some of them default, the assets of deposit banks - and therefore their equity - are reduced. By reducing the capital ratio, the rule incentivizes deposit banks to 
Table 6: Impact of macroprudential rules on key variables

\begin{tabular}{lrrrrrr}
\hline \hline & $\begin{array}{c}\text { I } \\
\text { Constant } \\
\text { rule }\end{array}$ & $\begin{array}{c}\text { II } \\
\text { Output } \\
\text { growth } \\
(i=\Delta y)\end{array}$ & $\begin{array}{c}\text { III } \\
\text { Credit } \\
\text { growth } \\
(i=\Delta S)\end{array}$ & $\begin{array}{c}\text { IV } \\
\text { SEL }\end{array}$ & $\begin{array}{c}\text { V } \\
\text { Output } \\
\text { growth } \\
\text { and SEL }\end{array}$ & $\begin{array}{c}\text { VI } \\
\text { Credit } \\
\text { growth } \\
\text { and SEL }\end{array}$ \\
\hline$\beta_{i}$ & 0 & 1.75 & 1.37 & 0 & 1.96 & 0.92 \\
$\beta_{S E L}$ & 0 & 0 & 0 & 0.17 & 0.1 & 0.15 \\
Welfare & -125.86 & -125.85 & -125.80 & -125.75 & -125.75 & -125.74 \\
\hline Output & -5.03 & -5.29 & -5.11 & -3.71 & -3.94 & -3.77 \\
Consumption & -2.88 & -2.66 & -2.11 & -2.69 & -2.59 & -2.56 \\
Investment & -15.20 & -16.31 & -16.57 & -10.99 & -12.09 & -11.40 \\
Hours worked & -5.46 & -5.75 & -5.63 & -4.15 & -4.49 & -4.25 \\
Inflation rate & -2.78 & -2.87 & -2.91 & -2.03 & -2.09 & -2.06 \\
Risk-free interest rate & -3.24 & -3.34 & -3.32 & -2.32 & -2.40 & -2.36 \\
Securities & -20.78 & -19.52 & -11.53 & -10.07 & -9.54 & -6.41 \\
Deposits & -13.68 & -13.70 & -14.73 & -25.68 & -25.07 & -24.36 \\
\hline Merchant bank leverage & 1.88 & 1.87 & 1.84 & 1.80 & 1.79 & 1.81 \\
Deposit bank leverage & 13.26 & 16.42 & 19.32 & 12.02 & 13.83 & 12.58 \\
Merchant bank prob. of default & 25.62 & 23.89 & 19.84 & 16.71 & 15.71 & 17.26 \\
Deposit bank prob. of default & 6.20 & 9.36 & 11.32 & 4.24 & 6.13 & 5.00 \\
SEL & 2.83 & 5.07 & 7.02 & 1.89 & 3.13 & 2.34 \\
\hline
\end{tabular}

lend more than they normally would. However, this move also increases deposit banks' risk of default. Indeed, the probability of default increases to $9.4 \%$ for deposit banks, so they are more reluctant to finance the firm's investment, which decreases by $16.3 \%$. Eventually, output suffers more in the crisis: the loss is equal to $5.3 \%$ instead of $5 \%$ in the case with constant capital ratio. Ultimately, SEL is also higher (5.1\% of GDP).

When the business cycle variable is credit growth, the mechanisms observed in the case of output growth are reinforced (column III). Losses of welfare and consumption are again reduced, but at the cost of a lower investment and a more fragile banking system. SEL increases to $7 \%$ of GDP. ${ }^{17}$

Clearly, these results illustrate the trade-off regulators face: increasing the amount of credit available to the economy in a crisis also makes banks more fragile and more likely to default. In column IV, we report the rule based on SEL only. This rule is not countercyclical. Indeed, it does not reduce the capital requirement during the crisis, but instead, banks anticipate that the regulator will increase the capital ratio after the end of the crisis in order to address their current capital shortfall. Because the government anticipates that deposit banks will be relatively safer in the next period, it requires a lower insurance premium, which reduces the cost

\footnotetext{
${ }^{17}$ When welfare is maximized, while allowing both output and credit growth in the rule, the optimal rule includes only credit growth. This result reflects that the use of credit growth in the policy rule is a more effective indicator to maximize welfare.
} 
of banks' financing. Deposit banks can lend more to merchant banks, which also benefit from a lower interbank rate and provide more financing to firms so that investment decreases less during the crisis. Merchant banks' default is less likely than it is in the constant rule, the equity of the merchant and deposit banks decreases less, which reduces SEL to $1.9 \%$. Because the real rate decreases less than they do with the constant rule, deposits are more reduced and consumption is barely improved. However, as the economy recovers more quickly, overall welfare is reduced less. Interestingly, using this indicator in the macroprudential rule helps reduce the loss in welfare due to the crisis because it curbs the expectation of a distress in the financial system.

When macroprudential rules involve a combination of a business cycle indicator and SEL, we now obtain countercyclical dynamics of the capital ratio. Welfare is again improved, although consumption suffers more than it does in the case with credit growth as a unique indicator of the rule (columns V and VI). In fact, the welfare improvement is attributable to a lower decline in investment, which is more favorable to future growth. In parallel, the probability of default of deposit banks and SEL are substantially reduced. The more effective rule is then the one comprising credit growth and SEL.

So far, we have considered rules that react instantly to business cycle indicators. However, it may be desirable for the macroprudential rule to contain a certain degree of inertia, as in the monetary policy rule. We introduce a lag to the capital ratio with a smoothing coefficient equal to 0.25 . We find that the negative impact of the crisis on welfare can be further mitigated by improving the banking system's stability (Table 7). Banks reduce their lending less, so firms reduce their investment less. Therefore, even if consumption suffers slightly more, welfare globally improves. Given the rule with credit growth and SEL, we also obtain that deposit banks' probability of default and aggregate SEL increase substantially less than in the constant capital ratio case.

\section{Conclusion}

In this paper, we present a macro-finance DSGE model that allows us to measure the capital shortfall of the banking system in a severe adverse scenario. The model incorporates a rich banking sector. It includes two types of banks: merchant banks, which provide funds to producing firms to finance their capital equipment through long-term claims, and deposit banks, which receive deposits from households and provide financing to merchant banks through collateralized loans. The two mechanisms are likely to generate capital shortfall among the de- 
Table 7: Impact of macroprudential rules on key variables - with smoothing

\begin{tabular}{lrrrrr}
\hline \hline & $\begin{array}{c}\text { I } \\
\text { Output } \\
\text { growth } \\
(i=\Delta y)\end{array}$ & $\begin{array}{c}\text { II } \\
\text { Credit } \\
\text { growth } \\
(i=\Delta S)\end{array}$ & $\begin{array}{c}\text { III } \\
\text { SEL }\end{array}$ & $\begin{array}{c}\text { IV } \\
\text { Output } \\
\text { growth } \\
\text { and SEL }\end{array}$ & $\begin{array}{c}\text { V } \\
\text { Credit } \\
\text { growth } \\
\text { and SEL }\end{array}$ \\
\hline$\beta_{i}$ & 0.66 & 1.55 & 0 & 1.90 & 0.46 \\
$\beta_{S E L}$ & 0 & 0 & 0.29 & 0.22 & 0.37 \\
Welfare & -125.86 & -125.81 & -125.72 & -125.72 & -125.72 \\
\hline Output & -5.13 & -5.14 & -3.23 & -3.37 & -3.08 \\
Consumption & -2.84 & -2.14 & -2.71 & -2.70 & -2.75 \\
Investment & -15.48 & -16.66 & -9.35 & -9.81 & -8.75 \\
Hours worked & -5.57 & -5.65 & -3.69 & -3.85 & -3.52 \\
Inflation rate & -2.82 & -2.93 & -1.60 & -1.58 & -1.48 \\
Risk-free interest rate & -3.28 & -3.34 & -1.83 & -1.82 & -1.69 \\
Securities & -20.72 & -13.12 & -7.38 & -7.18 & -6.45 \\
Deposits & -13.78 & -13.63 & -29.04 & -29.14 & -29.98 \\
\hline Merchant bank leverage & 1.88 & 1.84 & 1.79 & 1.78 & 1.79 \\
Deposit bank leverage & 13.99 & 19.45 & 11.81 & 12.77 & 11.51 \\
Merchant bank prob. of default & 25.28 & 20.53 & 15.25 & 14.45 & 15.08 \\
Deposit bank prob. of default & 7.03 & 11.46 & 3.89 & 4.86 & 3.53 \\
SEL & 3.37 & 7.08 & 1.71 & 2.33 & 1.51 \\
\hline
\end{tabular}

Note: The rule is now: $\frac{\vartheta_{t}}{\vartheta}=\left(\frac{\vartheta_{t-1}}{\vartheta}\right)^{\rho_{\vartheta}}\left(\left(\frac{Y_{t}}{\mu_{z} Y_{t-1}}\right)^{\beta_{\Delta y}}\left(\frac{S_{t}}{\mu_{z} S_{t-1}}\right)^{\beta_{\Delta S}}\left(\frac{S E L_{t}}{Y_{t}}\right)^{\beta_{S E L}}\right)^{\left(1-\rho_{\vartheta}\right)}$, with $\rho_{\vartheta}=0.25$.

posit banks in a financial crisis. First, given that the loan is secured by the long-term claim on firm revenues, a drop in the market value of firm securities forces merchant banks to delever, resulting in a decrease in the value of the loan. Second, a default of merchant banks or a loss in the risky assets of the deposit banks may force deposit banks to default if they are unable to repay the face value of their deposits.

The model is estimated for the euro area economy for the 1985-2007 period. The impulse response analysis to the various shocks confirms that the model correctly reproduces the responses of macroeconomic variables found in previous research and generates a consistent behavior for both types of banks. Then, we consider the effect of a crisis on capital shortfalls. We define a crisis as a combination of a negative investment shock and a positive volatility shock and use the 2008-2009 crisis to calibrate the magnitude of the shocks. We determine the expected loss of deposit banks under the crisis scenario. The magnitude of the capital shortfall is similar to empirical estimates of the equity loss of commercial banks in the 2008-2009 crisis (Acharya and Steffen, 2014).

Finally, we investigate the potential benefit of a countercyclical capital ratio. We obtain that standard rules (targeting output or credit growth only) can reduce the strength of the recession but at the cost of a higher risk to the financial system. Using a rule involving both 
output and credit growth and SEL allows the regulator to improve both economic growth and the health of the financial system. These results illustrate the importance of designing a macroprudential rule that allows for a countercyclical capital ratio while ensuring the stability of the financial system. Attempting to boost credit while rendering banks more fragile does not result in significant increase in investment and output. In contrast, ensuring that capital shortfall does not increase excessively enables banks to increase their financing to firms. 


\section{References}

Acharya, V., Viswanathan, S., 2011. Leverage, moral hazard, and liquidity. Journal of Finance 66(1), 99-138.

Acharya, V. V., Bharath, S. T., Srinivasan, A., 2007. Does industry-wide distress affect defaulted firms? - Evidence from creditor recoveries. Journal of Financial Economics 85, 787-821.

Acharya, V. V., Pedersen, L. H., Philippon, T., Richardson, M. P., 2012. Measuring systemic risk, CEPR Discussion Paper no. 8824.

Acharya, V. V., Steffen, S., 2014. Falling short of expectations? Stress-testing the European banking system, CEPS Policy Brief no. 315.

Adrian, T., Shin, H. S., 2010. Liquidity and leverage. Journal of Financial Intermediation 19, 418-437.

Adrian, T., Shin, H. S., 2014. Procyclical leverage and Value-at-Risk. Review of Financial Studies $27,373-403$.

Alpanda, S., Cateau, G., Meh, C., 2014. A policy model to analyze macroprudential regulations and monetary policy, BIS Working Paper no. 461.

An, S., Schorfheide, F., 2007. Bayesian analysis of DSGE models. Econometric Reviews 26(2-4), $113-172$.

Andolfatto, D., 1996. Business cycles and labor-market search. American Economic Review 86, $112-132$.

Andrade, P., Breckenfelder, J., De Fiore, F., Karadi, P., Tristani, O., 2016. The ECB's asset purchase programme - An early assessment, ECB Working Paper no. 1956.

Angelini, P., Neri, S., Panetta, F., 2014. The interaction between capital requirements and monetary policy. Journal of Money, Credit and Banking 46(6), 1073-1112.

Angeloni, I., Faia, E., 2013. Capital regulation and monetary policy with fragile banks. Journal of Monetary Economics 60, 311-324.

Begenau, J., Landvoigt, T., 2016. Financial regulation in a quantitative model of the modern banking system, Working Paper. Available at SSRN: https://ssrn.com/abstract=2748206. 
Bernanke, B., Gertler, M., 1989. Agency costs, net worth, and business fluctuations. American Economic Review 79, 14-31.

Bernanke, B., Gertler, M., Gilchrist, S., 1999. The financial accelerator in a quantitative business cycle framework. In: Taylor, J., Woodford, M. (Eds.), Handbook of Macroeconomics, Volume 1. pp. 1341-1393.

Brinkmeyer, H., 2014. Drivers of Bank Lending: New Evidence from the Crisis. Springer Gabler.

Brownlees, C. T., Engle, R. F., 2017. SRISK: A conditional capital shortfall measure of systemic risk. Review of Financial Studies 30(1), 48-79.

Brunnermeier, M., Pedersen, L., 2009. Market liquidity and funding liquidity. Review of Financial Studies 22, 2201-2238.

Brunnermeier, M., Sannikov, Y., 2014. A macroeconomic model of the financial sector. American Economic Review 104, 379-421.

Caballero, R. J., Simsek, A., 2013. Fire sales in a model of complexity. Journal of Finance 68, 2549-2587.

Cahn, C., Matheron, J., Sahuc, J.-G., 2017. Assessing the macroeconomic effects of LTROs during the great recession. Journal of Money, Credit, and Banking 49, 1443-1482.

Carlstrom, C., Fuerst, T., 1989. Agency costs, net worth, and business fluctuations: A computable general equilibrium analysis. American Economic Review 87, 893-910.

Christiano, L. J., Motto, R., Rostagno, M., 2010. Financial factors in economic fluctuations, ECB Working Paper no. 1192.

Christiano, L. J., Motto, R., Rostagno, M., 2014. Risk shocks. American Economic Review 104, 27-65.

Clerc, L., Derviz, A., Mendicino, C., Moyen, S., Nikolov, K., Stracca, L., Suarez, J., Vardoulakis, A. P., 2015. Capital regulation in a macroeconomic model with three layers of default. International Journal of Central Banking 11(3), 9-63.

Collard, F., Dellas, H., Diba, B., Loisel, O., 2017. Optimal monetary and prudential policies. American Economic Journal: Macroeconomics 9, 40-87. 
Coval, J. D., Stafford, E., 2007. Asset fire sales and purchases in equity markets. Journal of Financial Economics 86, 479-512.

De Walque, G., Pierrard, O., Rouabah, A., 2010. Financial (in)stability, supervision and liquidity injections: A dynamic general equilibrium approach. Economic Journal 120, 1234-1261.

Dib, A., 2010. Capital requirement and financial frictions in banking: Macroeconomic implications, Bank of Canada Working Paper no. 2010-26.

Druant, M., Fabiani, S., Kezdi, G., Lamo, A., Martins, F., Sabbatini, R., 2012. Firms' price and wage adjustment in Europe: Survey evidence on nominal stickiness. Labour Economics 19, $772-782$.

Duarte, F., Eisenbach, T. M., 2013. Fire-sale spillovers and systemic risk, Federal Reserve Bank of New York Staff Report no. 645.

ECB, 2014. Aggregate report on the comprehensive assessment, october.

ECB, 2016. Business investment developments in the Euro Area since the crisis, ECB Economic Bulletin issue 7.

Everaert, L., Schule, W., 2008. Why it pays to synchronize structural reforms in the Euro Area across markets and countries. IMF Staff Papers 55(2), 356-366.

Fagan, G., Henry, J., Mestre, R., 2005. An Area-Wide Model (AWM) for the Euro-Area. Economic Modelling 22, 39-59.

Galati, G., Moessner, R., 2012. Macroprudential policy - A literature review. Journal of Economic Survey 27(5), 846-878.

Gelain, P., Ilbas, P., 2017. Monetary and macroprudential policies in an estimated model with financial intermediation. Journal of Economic Dynamics and Control 78, 164-189.

Gertler, M., Karadi, P., 2011. A model of unconventional monetary policy. Journal of Monetary Economics 58, 17-34.

Gertler, M., Kiyotaki, N., 2010. Financial intermediation and credit policy in business cycle analysis. In: Friedman, B., Woodford, M. (Eds.), Handbook of Monetary Economics, Volume 3. Elsevier, pp. 547-599.

Gilchrist, S., Zakrajšek, E., 2012. Credit spreads and business cycle fluctuations. American Economic Review 102(4), 1692-1720. 
Gilson, S. C., 1997. Transactions costs and capital structure choice: Evidence from financially distressed firms. Journal of Finance 52, 161-196.

He, Z., Khang, I. G., Krishnamurthy, A., 2010. Balance sheet adjustments during the 2008 crisis. IMF Economic Review 58, 118-156.

He, Z., Krishnamurthy, A., 2012. A model of capital and crises. Review of Economic Studies $79,735-777$.

He, Z., Krishnamurthy, A., 2013. Intermediary asset pricing. American Economic Review 103, 732-770.

He, Z., Krishnamurthy, A., 2014. A macroeconomic framework for quantifying systemic risk, NBER Working Paper no. 19885.

Huang, X., Zhou, H., Zhu, H., 2011. Systemic risk contributions. Journal of Financial Services Research 42, 55-83.

Jermann, U., Quadrini, V., 2012. Macroeconomic effects of financial shocks. American Economic Review 102(1), 238-271.

Jobst, A. A., Gray, D. F., 2013. Systemic contingent claims analysis - estimating market-implied systemic risk. IMF Working Paper No. 13/54.

Jondeau, E., Khalilzadeh, A., 2017. Collateralization, leverage, and stressed expected loss. Journal of Financial Stability 33, 226-243.

Justiniano, A., Primiceri, G. E., Tambalotti, A., 2010. Investment shocks and business cycles. Journal of Monetary Economics 57(2), 132-145.

Kiyotaki, N., Moore, J., 1997. Credit cycles. Journal of Political Economy 105, 211-248.

Levine, P., Lima, D., 2015. Policy mandates for macro-prudential and monetary policies in a new keynesian framework, ECB Working Paper no. 1784.

Martinez-Miera, D., Suarez, J., 2014. Banks' endogenous systemic risk taking, Working Paper.

McAdam, P., Willman, A., 2013. Medium run redux. Macroeconomic Dynamics 17(4), 695-727.

Merz, M., 1995. Search in the labor market and the real business cycle. Journal of Monetary Economics 36, 269-300. 
Nuño, G., Thomas, C., 2017. Bank leverage cycles. American Economic Journal: Macroeconomics $9,32-72$.

Ohanian, L., Raffo, A., 2012. Aggregate hours worked in OECD countries: New measurement and implications for business cycles. Journal of Monetary Economics 59, 40-56.

Pietrunti, M., 2017. Financial frictions and the real economy, European Systemic Risk Board Working Paper no. 41.

Rubio, M., Carrasco-Gallego, J. A., 2014. Macroprudential and monetary policies: Implications for financial stability and welfare. Journal of Banking and Finance 49, 326-336.

Sahuc, J.-G., Smets, F., 2008. Differences in interest rate policy at the ECB and the Fed: An investigation with a medium-scale DSGE model. Journal of Money, Credit and Banking 40(24), 505-521.

Shleifer, A., Vishny, R. W., 2011. Fire sales in finance and macroeconomics. Journal of Economic Perspectives 25, 29-48.

Smets, F., Wouters, R., 2003. An estimated dynamic stochastic general equilibrium model of the Euro Area. Journal of the European Economic Association 1, 1123-1175.

Smets, F., Wouters, R., 2007. Shocks and frictions in US business cycles: A Bayesian DSGE approach. American Economic Review 97, 586-606. 


\section{Appendix}

\section{A Complete Model}

\section{A.1 Timing}

In period $t$, the following sequence of events and decisions occurs:

1. Firms buy new capital equipment by selling a long-term claim to merchant banks. Banks optimally determine the composition of their balance sheet (cash holding, loan).

2. Shocks are observed, including the idiosyncratic shock on the quality of firm's capital investment.

3. Production occurs. Firms' revenues of firms depend on the realization of the shocks. The value of the securities held by merchant banks is observed. Banks adjust balance sheet quantities accordingly (in case of fire sale or default).

4. In case of a deposit bank default, the government repays deposits of defaulting banks to households.

\section{A.2 Household Sector}

\section{A.2.1 Household}

The economy is inhabited by a continuum of differentiated households, indexed by $h \in[0,1]$. We adopt the large family assumption of Merz (1995) and Andolfatto (1996) by assuming that each household contains every type of differentiated labor $L_{t}(h)$. There is a perfect consumption insurance within a family. Each household has a large number of firms including entrepreneurs and bankers, but we defer our discussion of these agents to the next subsection. A typical household selects a sequence of consumptions and savings that is deposited in a bank. Household $h$ 's objective is to maximize its lifetime utility, given by:

$$
\mathrm{E}_{t} \sum_{s=0}^{\infty} \beta^{s} \varepsilon_{b, t+s}\left[\log \left(C_{t+s}(h)-\gamma C_{t+s-1}\right)-\frac{\chi}{1+v} L_{t+s}(h)^{1+v}\right]
$$

subject to the sequence of constraints:

$$
\left(1+\tau_{c}\right) P_{t} C_{t}(h)+D_{t}(h)=\left(1-\tau_{w}\right) W_{t}(h) L_{t}(h)+R_{t-1} D_{t-1}(h)+\operatorname{Div}_{t}(h)+\operatorname{Tr}_{t}(h),
$$


where $\mathrm{E}_{t}$ denotes the mathematical expectation operator conditional upon information available at time $t, C_{t}(h)$ is private consumption, $P_{t}$ is the aggregate price level, $W_{t}(h)$ and $L_{t}(h)$ denote the nominal wage rate and the labor supply of type- $h$ household, $D_{t}(h)$ denotes deposits, paying the risk-free nominal interest rate $R_{t}, \operatorname{Div}_{t}(h)$ denotes the net transfers from all family members to the family, and $\operatorname{Tr}_{t}(h)$ denotes the nominal transfers (lump-sum taxes if negative) from the government. $\beta \in(0,1)$ is the subjective discount factor, $\gamma \in[0,1)$ is the habit parameter, $\chi>0$ is a scale parameter, $v \geq 0$ governs the elasticity of labor supply, $\tau_{c}$ and $\tau_{w}$ denote the tax rates on consumption and labor income, respectively. Section 2.2.2 describes the dynamics of the preference shock, denoted by $\varepsilon_{b, t}$, and how the insurance premium $\Pi_{i n s, t}$ is determined.

Every household has a market power on its labor and sets wages according to a staggering mechanism. In each period, a fraction $\theta_{w}$ of households cannot choose its wage optimally, but adjusts it to keep up with the increase in the general wage level in the previous period according to the indexation rule $W_{t}(h)=\left[\left(\mu_{z} \pi\right)^{1-\gamma_{w}}\left(\pi_{t-1}\right)^{\gamma_{w w}}\right] W_{t-1}(h)$, where $\pi_{t} \equiv P_{t} / P_{t-1}$ represents the gross inflation rate, $\pi$ is steady-state (or trend) inflation, and coefficient $\gamma_{w} \in$ $[0,1]$ is the degree of indexation to past wages. The remaining fraction of workers chooses instead an optimal wage, subject to the labor demand function $L_{t}(h)$.

As deposit banks can default, deposits are insured by the government: The deposit bank pays a deposits insurance premium, $\Pi_{i n s, t}$, to the government, so that the deposit rate actually paid by the bank at date $t$ is $R_{d, t}=R_{t}+\Pi_{\text {ins }, t}$.

\section{A.2.2 Employment agency}

Each household $h$ is a monopolistic supplier of specialized labor $L_{t}(h)$. At every point in time $t$, a large number of competitive employment agencies combine households' labor into a homogeneous labor input according to $L_{t}=\left[\int_{0}^{1} L_{t}(h)^{\frac{\zeta_{w}-1}{\zeta w}} \mathrm{~d} h\right]^{\frac{\zeta w}{\zeta w-1}}$. Profit maximization by the employment agency implies the labor demand function $L_{t}(h)=\left(\frac{W_{t}(h)}{W_{t}}\right)^{-\zeta_{w}} L_{t}$, where $W_{t}(h)$ is the wage paid by the agencies to the household supplying labor variety $h$, while $W_{t} \equiv\left[\int_{0}^{1} W_{t}(h)^{\zeta_{w}-1} \mathrm{~d} h\right]^{\frac{1}{\zeta w-1}}$ is the wage paid by the firms for the homogeneous labor input sold by the agency. The parameter $\zeta_{w}>0$ is the elasticity of substitution between any two labor types and $\varepsilon_{w}=\zeta_{w} /\left(\zeta_{w}-1\right)$ denotes the steady-state wage markup. 


\section{A.3 Production Sector}

\section{A.3.1 Intermediate goods producer}

Competitive firms produce intermediate goods that are sold to retailers. Each producer, indexed by $f \in[0,1]$, finances its capital acquisition each period by obtaining funds from a merchant bank, which invests in only one project. The firm sells a long-term claim on its future cash flows to the bank. The claim at time $t$ is equal to the value of the capital units acquired at the end of period $t-1$, i.e., $S_{t}(f)=Q_{t-1} \bar{K}_{t-1}(f)$, where $Q_{t-1}$ is the price of a unit of capital and $\bar{K}_{t-1}(f)$ the number of units of capital purchased. At the beginning of period $t$, after all agents have made their decisions, the quality of capital is revealed to the firms though the realization of an idiosyncratic shock $\omega_{t}(f)$, so that the efficient capital is $K_{t}(f)=\omega_{t}(f) \bar{K}_{t-1}(f)$. As in Bernanke et al. (1999) and Christiano et al. (2014), we assume that $\omega_{t}(f)$ has a unit mean log-normal cross-sectional distribution that is independently drawn across time and across firms.

Intermediate good $f$ is produced using a constant return to scale technology:

$$
Y_{m, t}(f)=\varepsilon_{a, t}\left[u_{t}(f) K_{t}(f)\right]^{\alpha}\left[Z_{t} L_{t}(f)\right]^{1-\alpha}-Z_{t} \Phi_{Y}(f),
$$

where $Y_{m, t}(f), K_{t}(f)$, and $L_{t}(f)$ denote output and the amounts of effective capital and labor used by firm $f$, respectively, $u_{t}(f)$ is the capital utilization rate, $\varepsilon_{a, t}$ is a transitory technology shock and $Z_{t}$ is a persistent labor-augmenting productivity factor. Adjusting the utilization rate entails a cost $\mathscr{S}_{u}\left(u_{t}(f)\right) K_{t}(f)$ (measured in units of final goods). The degree of convexity of the cost function is denoted by $\eta_{u}=\mathscr{S}_{u}^{\prime \prime}\left(u_{t}(f)\right) / \mathscr{S}_{u}^{\prime}\left(u_{t}(f)\right)$. Parameter $\alpha \in(0,1)$ denotes the capital share and $\Phi_{Y}(f)>0$ is a fixed cost of production that ensures that profits are zero in steady state.

Let $P_{m, t}(f)$ be the price of intermediate goods. Nominal profit is equal to:

$$
P_{m, t}(f) Y_{m, t}(f)-W_{t}(f) L_{t}(f)-P_{t} \mathscr{S}_{u}\left(u_{t}(f)\right) K_{t}(f)
$$

Assume further that the replacement price of used capital is fixed at unity. Then at time $t$, the firm chooses the utilization rate and labor demand that satisfy:

$$
\frac{W_{t}}{P_{m, t}(f)}=(1-\alpha) \varepsilon_{a, t} Z_{t}\left(\frac{u_{t}(f) K_{t}(f)}{Z_{t} L_{t}(f)}\right)^{\alpha}
$$


and

$$
\frac{P_{t}}{P_{m, t}(f)} \mathscr{S}_{u}^{\prime}\left(u_{t}(f)\right)=\alpha \varepsilon_{a, t}\left(\frac{u_{t}(f) K_{t}(f)}{Z_{t} L_{t}(f)}\right)^{\alpha-1} .
$$

Because labor is free to move across firms at no cost, nominal wage is equalized across firms. Given that the firm earns zero profit state by state, it simply pays out the ex post return to capital to the bank. Therefore, as the investment is financed one period in advance before the realization of the firm-specific shock, the gross nominal rate of return of the long-term claim held by the bank at time $t$ is known only at the end of period $t$. It is given by $\tilde{R}_{s, t}(f)=\omega_{t}(f) \hat{\mu}_{s, t}$ :

$$
\hat{\mu}_{s, t}=\frac{\left(1-\tau_{k}\right)\left(\mathscr{S}_{u}^{\prime}\left(u_{t}\right) u_{t}-\mathscr{S}_{u}\left(u_{t}\right)\right) P_{t}+(1-\delta) Q_{t}}{Q_{t-1}}+\tau_{k} \delta
$$

where $\tau_{k}$ is the tax rate on capital and $\delta \in[0,1]$ is the depreciation rate of capital.

\section{A.3.2 Capital goods producer}

Capital producers are competitive firms that buy back old capital units, add to these new capital units using the final goods as input (subject to an adjustment cost) and sell the new capital to firms at price $Q_{t}$. The objective of a capital producer is to choose a contingent plan for investment $I_{t}$ so as to maximize:

$$
\mathrm{E}_{t} \sum_{s=0}^{\infty} \beta^{s} \frac{\Lambda_{t+s}}{\Lambda_{t}}\left[Q_{t+s} \varepsilon_{i, t+s}\left(1-\mathscr{S}_{i}\left(\frac{I_{t+s}}{I_{t+s-1}}\right)\right)-P_{t+s}\right] I_{t+s},
$$

where $\mathscr{S}_{i}($.$) is the adjustment cost function, which satisfies \mathscr{S}_{i}(1)=\mathscr{S}_{i}^{\prime}(1)=0$ and $\mathscr{S}_{i}^{\prime \prime}(1)=$ $\eta_{k}>0$, and $\varepsilon_{i, t}$ is an investment-specific shock, which captures exogenous variation in investment efficiency (Justiniano et al., 2010). $\Lambda_{t+s}$ is the marginal utility of consumption for the representative household, which owns the capital producer.

The aggregate capital stock in the economy evolves according to:

$$
\bar{K}_{t+1}=(1-\delta) \bar{K}_{t}+\varepsilon_{i, t}\left(1-\mathscr{S}_{i}\left(\frac{I_{t}}{I_{t-1}}\right)\right) I_{t}
$$

\section{A.3.3 Retail firm}

Nominal rigidities are introduced into the model by assuming that a continuum of monopolistic retail firms, indexed by $\varsigma \in[0,1]$, purchase intermediate goods before transforming them into a continuum of differentiated goods $Y_{t}(\varsigma)$, without costs. This continuum of differentiated goods is then combined with the help of a CES bundling technology to obtain the final 
good: $Y_{t}=\left[\int_{0}^{1} Y_{t}(\zeta)^{\frac{\zeta p-1}{\zeta p}} \mathrm{~d} \varsigma\right]^{\frac{\zeta p}{\zeta p-1}}$, where the parameter $\zeta_{p}>0$ is the elasticity of substitution between any two types of intermediate goods and $\varepsilon_{p}=\zeta_{p} /\left(\zeta_{p}-1\right)$ denotes the steady-state price markup.

The retail firm sets its price according to a staggering mechanism. In each period, a fraction $\theta_{p}$ of firms cannot choose its price optimally, but adjusts it to keep up with the increase in the general price level in the previous period according to the indexation rule $P_{t}(\varsigma)=$ $\left(\pi^{1-\gamma_{p}} \pi_{t-1}^{\gamma_{p}}\right) P_{t-1}(\varsigma)$, where the coefficient $\gamma_{p} \in[0,1]$ indicates the degree of indexation to past prices. The remaining fraction of firms chooses its price $P_{t}^{\star}(\varsigma)$ optimally, by maximizing the present discounted value of future profits:

$$
\mathrm{E}_{t} \sum_{s=0}^{\infty}\left(\beta \theta_{p}\right)^{s} \frac{\Lambda_{t+s}}{\Lambda_{t}}\left[\Pi_{t, t+s}^{p} P_{t}^{\star}(\varsigma)-P_{m, t+s}(\varsigma)\right] Y_{t+s}(\varsigma)
$$

where

$$
\Pi_{t, t+s}^{p}= \begin{cases}\prod_{\tau=1}^{s} \pi^{1-\gamma_{p}} \pi_{t+\tau-1}^{\gamma_{p}} & s>0 \\ 1 & s=0\end{cases}
$$

taking the demand for its good and the corresponding price as given. Cost minimization yields the demand for each retailer's good: $Y_{t}(\varsigma)=\left(\frac{P_{t}(\varsigma)}{P_{t}}\right)^{-\zeta_{p}} Y_{t}$, with $P_{t} \equiv\left[\int_{0}^{1} P_{t}(\varsigma)^{\zeta_{p}-1} \mathrm{~d} \varsigma\right]^{\frac{1}{\zeta p-1}}$ the price aggregator.

\section{A.4 Banking Sector}

\section{A.4.1 Merchant Banks}

At the beginning of period $t$, the bank uses a fraction $a_{m, t}$ of its equity to finance the acquisition of capital equipment by the firm. Given the margin rate $\mathrm{h}$ imposed by the regulator, the bank can borrow $a_{m, t} N_{m, t} / \mathrm{h}$ and lend $S_{t}=a_{m, t} N_{m, t}(1+\mathrm{h}) / \mathrm{h}$ to the firm. The remaining equity $\left(1-a_{m, t}\right) N_{m, t}$ is kept in cash. Then the quality of the equipment bought by the firm is realized, which determines the return on the long-term claim at the end of period $t$, which we denote by $\tilde{R}_{s, t}$.

The schema below displays the different situations that a merchant bank can face, depending on $\tilde{R}_{s, t}$. When $\tilde{R}_{s, t}>\bar{R}_{s, t}$, the merchant bank does not face any margin call or can use its cash holding. When $\tilde{R}_{s, t} \in\left[\underline{R}_{s, t} ; \bar{R}_{s, t}\right]$, the bank has exhausted its cash holding and has to sell some of its risky securities to reduce its debt. When $\tilde{R}_{s, t} \leq \underline{R}_{s, t}$, the bank has exhausted all its securities and defaults. 


\begin{tabular}{lll} 
& \multicolumn{2}{c}{$\underline{R}_{s, t}$} \\
\hline Merch. bank default & Fire sales & Good time \\
Cash $=0$ & Cash $=0$ & Cash $>0$ \\
Securities $=0$ & Securities $>0$ & Securities $>0$ \\
(Case 3) & (Case 2) & (Case 1) \\
\hline
\end{tabular}

Case 1: Good time $\left(\tilde{R}_{s, t}>\bar{R}_{s, t}\right)$. Provided the value of securities is higher than the collateral requested by the deposit bank to secure the loan, no adjustment is requested from the merchant bank. In contrast, if the value of securities falls below the amount of collateral, $S_{t+1}<(1+$ h) $B_{t}$, the merchant bank reduces its debt using its free cash. In this case, the value of cash at $t+1$ is decreased to:

$$
\begin{aligned}
M_{m, t+1} & =\underbrace{R_{t} M_{m, t}}_{\text {interest received on cash }}-\underbrace{\left(R_{b, t}-1\right) B_{t}}_{\text {interest paid on debt }}-\underbrace{\left(B_{t}-\tilde{R}_{s, t} \frac{S_{t}}{1+\mathrm{h}}\right)}_{\text {debt reduction }(>0)} \\
& =\left[R_{t}\left(1-a_{m, t}\right)-R_{b, t} \frac{a_{m, t}}{\mathrm{~h}}+\tilde{R}_{s, t} \frac{(1+\mathrm{h}) a_{m, t}}{\mathrm{~h}}\right] N_{m, t} .
\end{aligned}
$$

Debt reduction is financed using cash only provided cash remains positive. This implies the following restriction:

$$
M_{m, t+1}>0 \Rightarrow \tilde{R}_{s, t}>\frac{1}{1+\mathrm{h}}\left(R_{b, t}-R_{t} \frac{\mathrm{h}\left(1-a_{m, t}\right)}{a_{m, t}}\right) \equiv \bar{R}_{s, t} .
$$

Provided $\tilde{R}_{s, t} \geq \bar{R}_{s, t}$, there is enough free cash to reduce the debt so that $B_{t+1}=S_{t+1} /(1+\mathrm{h})$. In this case, the expected equity is given by:

$$
\begin{aligned}
\mathrm{E}_{t} N_{m, t+1}^{(\text {good })} & =\mathrm{E}_{t}\left[N_{m, t+1} \mid \tilde{R}_{s, t}>\bar{R}_{s, t}\right] \\
& =\left[\mu_{s, t}^{(\text {good })} \frac{(1+\mathrm{h}) a_{m, t}}{\mathrm{~h}}+R_{t}\left(1-a_{m, t}\right)-R_{b, t} \frac{a_{m, t}}{\mathrm{~h}}\right] N_{m, t}
\end{aligned}
$$

where $\mu_{s, t}^{(\text {good })}=\mathrm{E}_{t}\left[\tilde{R}_{s, t} \mid \tilde{R}_{s, t}>\bar{R}_{s, t}\right]$ denotes the expected return on securities in good time.

Case 2: Fire sales $\left(\underline{R}_{s, t} \leq \tilde{R}_{s, t} \leq \bar{R}_{s, t}\right)$. When $\tilde{R}_{s, t} \leq \bar{R}_{s, t}$, the value of cash in Equation (A.4) is negative, meaning that there is not sufficient cash to cover the margin call. The merchant bank has to sell part of its assets (fire sale) to reduce its debt and satisfy the margin. In this case, debt 
should be reduced to maintain the relation:

$$
S_{t+1}=(1+\mathrm{h}) B_{t+1}
$$

To do so, the bank uses the available cash $\left(M_{m, t+1}\right)$ and sells part of its securities $\left(S_{t+1}-\tilde{R}_{s, t} S_{t}\right)$. We assume that, in such a fire sale, the merchant bank incurs a cost to sell securities with short notice. The cost is proportional to the value of securities sold, i.e., $-\phi\left(S_{t+1}-\tilde{R}_{s, t} S_{t}\right)>0$. Therefore, if the bank sells $\left(S_{t+1}-\tilde{R}_{s, t}\right) S_{t}$ of securities, its loan is reduced by $(1-\phi)\left(S_{t+1}-\right.$ $\left.\tilde{R}_{s, t} S_{t}\right)>0$. Eventually, the loan at $t+1$ decreases to:

$$
B_{t+1}=B_{t}-[\underbrace{R_{t} M_{m, t}-\left(R_{b, t}-1\right) B_{t}}_{\text {use of cash }(>0)}]+(1-\phi)[\underbrace{S_{t+1}-\tilde{R}_{s, t} S_{t}}_{\text {fire sale }(<0)}] .
$$

Therefore, in addition to the initial loss due to the firm's low return, the value of securities held by the bank will further decrease due to the fire sale:

$$
\begin{aligned}
S_{t+1} & =(1+\mathrm{h}) B_{t+1}=(1+\mathrm{h})\left[R_{b, t} B_{t}-R_{t} M_{m, t}+(1-\phi)\left(S_{t+1}-\tilde{R}_{s, t} S_{t}\right)\right] \\
& =\psi\left[R_{t} M_{m, t}-R_{b, t} B_{t}+\tilde{R}_{s, t}(1-\phi) S_{t}\right] \\
& =\psi\left[R_{t}\left(1-a_{m, t}\right)-R_{b, t} \frac{a_{m, t}}{\mathrm{~h}}+\tilde{R}_{s, t}(1-\phi) \frac{(1+\mathrm{h}) a_{t}}{\mathrm{~h}}\right] N_{m, t} .
\end{aligned}
$$

where $\psi=(1+\mathrm{h}) /((1+\mathrm{h})(1-\phi)-1)$ is positive, provided $\mathrm{h}>\phi$. We notice that the further reduction in securities is such that:

$$
\begin{aligned}
S_{t+1}-\tilde{R}_{s, t} S_{t} & =\psi\left[R_{t} M_{m, t}-R_{b, t} B_{, t}\right]-\left[\frac{\tilde{R}_{s, t} S_{t}}{1-(1+\mathrm{h})(1-\phi)}\right] \\
& =\psi\left[R_{t}\left(1-a_{m, t}\right)-R_{b, t} \frac{a_{m, t}}{\mathrm{~h}}+\tilde{R}_{s, t} \frac{a_{m, t}}{\mathrm{~h}}\right] N_{m, t} .
\end{aligned}
$$

The additional decrease in securities value is used by the merchant bank to repay part of its debt $B_{t+1}-B_{t}$. At the end of period $t$, the deposit bank receives the interest and principal of its loan $R_{b, t} B_{t}$. The new values $S_{t+1}$ and $B_{t+1}$ for next period satisfy the restriction.

The fire sale implies a decrease in the value of the equity of the bank due to the induced $\operatorname{cost} \phi\left(S_{t+1}-\tilde{R}_{s, t} S_{t}\right)<0$. The resulting value of equity is:

$$
\begin{aligned}
N_{m, t+1} & =\left[\tilde{R}_{s, t} \frac{(1+\mathrm{h}) a_{m, t}}{\mathrm{~h}}+R_{t}\left(1-a_{m, t}\right)-R_{b, t} \frac{a_{t}}{\mathrm{~h}}\right] N_{m, t}+\phi\left(S_{t+1}-\tilde{R}_{s, t} S_{t}\right) \\
& =\psi\left[\tilde{R}_{s, t}(1-\phi) a_{m, t}-R_{b, t} \frac{a_{m, t}}{1+\mathrm{h}}+R_{t} \frac{m\left(1-a_{m, t}\right)}{1+\mathrm{h}}\right] N_{m, t} .
\end{aligned}
$$


The merchant bank does not default if its deleveraging does not result in negative equity:

$$
N_{m, t+1}>0 \Rightarrow R_{t} \frac{\mathrm{h}\left(1-a_{m, t}\right)}{1+\mathrm{h}}-R_{b, t} \frac{a_{m, t}}{1+\mathrm{h}}+\tilde{R}_{s, t}(1-\phi) a_{m, t}>0
$$

so that

$$
\tilde{R}_{s, t}>\frac{1}{(1+\mathrm{h})(1-\phi)}\left(R_{b, t}-R_{t} \frac{\mathrm{h}\left(1-a_{m, t}\right)}{a_{m, t}}\right) \equiv \underline{R}_{s, t} \cdot
$$

We denote the expected equity of the merchant bank in case of fire sales by:

$$
\begin{aligned}
\mathrm{E}_{t} N_{m, t+1}^{(\text {fire })} & =\mathrm{E}_{t}\left[N_{m, t+1} \mid \tilde{R}_{s, t} \in\left[\underline{R}_{s, t} ; \bar{R}_{s, t}\right]\right] \\
& =\psi\left[\mu_{s, t}^{(f i r e)}(1-\phi) a_{m, t}+R_{t} \frac{\mathrm{h}\left(1-a_{m, t}\right)}{1+\mathrm{h}}-R_{b, t} \frac{a_{m, t}}{1+\mathrm{h}}\right] N_{m, t},
\end{aligned}
$$

where $\mu_{s, t}^{(\text {fire })}=\mathrm{E}_{t}\left[\tilde{R}_{s, t} \mid \tilde{R}_{s, t} \in\left[\underline{R}_{s, t} ; \bar{R}_{s, t}\right]\right]$.

As discussed in Section A.3.1, the rate of return of firm $f$ securities is $\tilde{R}_{s, t}=\omega_{t}(f) \hat{\mu}_{s, t}$, where $\hat{\mu}_{s, t}$ is given by Equation (A.3). As $\omega_{t}(f)$ has a unit mean log-normal cross-sectional distribution, $\tilde{R}_{s, t}$ is also log-normally distributed, with $\log \left(\tilde{R}_{s, t}\right) \sim N\left(\mu_{s, t}, \sigma_{s, t}^{2}\right)$, where $\mu_{s, t}$ and $\sigma_{s, t}^{2}$ are the cross-sectional mean and dispersion of the log-return on securities. ${ }^{18}$ Following Christiano et al. (2014), we allow the cross-sectional dispersion to vary through time. This risk shock, which we denote by $\sigma_{s, t}$, has an autoregressive dynamic, which we define in Section A.6.

As returns are log-normally distributed, probabilities and conditional expected returns are computed as follows: the probability to be below a given threshold $r, \operatorname{Pr}\left[\tilde{R}_{s, t} \leq r\right]$, is defined as the cdf $L N\left(r ; \mu_{s, t}, \sigma_{s, t}^{2}\right)$. The expected return conditional on $\tilde{R}_{s, t}$ being below $r$ is defined as:

$$
\mathrm{E}_{t}\left[\tilde{R}_{s, t} \mid \tilde{R}_{s, t} \leq r\right]=\frac{\exp \left(\mu_{s, t}+\sigma_{s, t}^{2} / 2\right) \Phi\left(\left(\log (r)-\left(\mu_{s, t}+\sigma_{s, t}^{2}\right)\right) / \sigma_{s, t}\right)}{\operatorname{Pr}\left[\tilde{R}_{s, t} \leq r\right]}
$$

\section{A.4.2 Deposit Banks}

At the beginning of period $t$, the deposit bank receives deposits $D_{t}$ from households, lends $B_{t}$ to the merchant bank, and decides to keep a fraction $\left(1-a_{d, t}\right)$ of its deposits in cash. Its equity has to satisfy the capital requirement imposed by the regulator, so that its equity should be larger than a fraction $\vartheta$ of its risk-weighted assets.

\footnotetext{
${ }^{18}$ We deduce that the expected return and the dispersion of $\tilde{R}_{s, t}$ are $\hat{\mu}_{s, t}=\mathrm{E}_{t}\left[\tilde{R}_{s, t}\right]=\exp \left(\mu_{s, t}+\sigma_{s, t}^{2} / 2\right)-1$ and $\hat{\sigma}_{s, t}^{2}=V_{t}\left[\tilde{R}_{s, t}\right]=\exp \left(2 \mu_{s, t}+\sigma_{s, t}^{2}\right)\left(\exp \left(\sigma_{s, t}^{2}\right)-1\right)$, respectively, where $\hat{\mu}_{s, t}$ is defined in Equation (A.3). Working with $\mu_{s, t}$ and $\sigma_{s, t}^{2}$ avoids negative quantities.
} 
The schema below displays the different situations that a deposit bank can meet, depending on the value of the return on securities at the end of the period. When $\tilde{R}_{s, t}>\underline{R}_{s, t}$, the deposit bank does not suffer from any loss on its loan to the merchant bank. When $\tilde{R}_{s, t} \in\left[\underline{R}_{s d, t}, \underline{R}_{s, t}\right]$, it suffers from a loss but does not default. Last, when $\tilde{R}_{s, t} \leq \underline{R}_{s d, t}$, the deposit bank defaults.

\begin{tabular}{|c|c|c|}
\hline & \multicolumn{2}{|c|}{$\underline{R}_{s, t}$} \\
\hline Dep. bank default & Merch. bank default & Normal time \\
\hline Cash $=0$ & Cash $=0$ & Cash $>0$ \\
\hline Loan $=0$ & Loss on the loan & No loss on the loan \\
\hline (Case $\left.3^{\prime}\right)$ & (Case 2') & (Case $\left.1^{\prime}\right)$ \\
\hline
\end{tabular}

Case 1': No loss on the loan to the merchant bank $\left(\tilde{R}_{s, t}>\underline{R}_{s, t}\right)$. When $\tilde{R}_{s, t}>\underline{R}_{s, t}$, the loan by the deposit bank to the merchant bank is fully repaid, even if this is done at the cost of a fire sale. The merchant bank repays its debt by selling a fraction of its risky assets. Therefore, for the deposit bank, the ex-post return on the loan is $\tilde{R}_{b, t}=R_{b, t}$ and the value of its equity is:

$$
\begin{aligned}
\mathrm{E}_{t} N_{d, t+1}^{(\text {normal })} & =\mathrm{E}_{t}\left[N_{d, t+1} \mid \text { Normal time and Fire sales }\right] \\
& =\left[R_{t}+\frac{B_{t}}{N_{d, t}}\left(R_{b, t}-R_{t}\right)-\frac{D_{t}}{N_{d, t}}\left(R_{d, t}-R_{t}\right)\right] N_{d, t} .
\end{aligned}
$$

Case 2': Merchant bank default but deposit bank survival $\left(\tilde{R}_{s, t} \in\left[\underline{R}_{s d, t}, \underline{R}_{s, t}\right]\right)$. The merchant bank defaults and the ex-post return on the loan is given by what is left to the deposit bank after the default of the merchant bank, i.e., the value of the liquidated assets, $\tilde{R}_{s, t}(1-\xi) S_{t}$, and the cash, $R_{t} M_{m, t}$. Therefore, we have:

$$
\tilde{R}_{b, t} B_{t}=\tilde{R}_{s, t}(1-\xi) S_{t}+R_{t} M_{m, t}
$$

The deposit bank survives if the value of its assets is sufficient to repay its deposits in $t+1$ (or $\left.N_{d, t+1}>0\right)$, so that $\tilde{R}_{b, t} B_{t}+R_{t} M_{d, t}>R_{d, t} D_{t}$, which implies $\tilde{R}_{s, t}(1-\xi) S_{t}>R_{d, t} D_{t}-R_{t}\left(M_{m, t}+\right.$ $\left.M_{d, t}\right)$. This implies that the ex-post return on securities satisfies the inequality:

$$
\tilde{R}_{s, t}>\frac{1}{(1+\mathrm{h})(1-\xi)}\left[R_{d, t} \frac{D_{t}}{B_{t}}-R_{t} \frac{\left(1-a_{d, t}\right) N_{d, t}}{B_{t}}-R_{t} \frac{\mathrm{h}\left(1-a_{m, t}\right)}{a_{m, t}}\right] \equiv \underline{R}_{s d, t} .
$$


The deposit bank equity is affected by the default of the merchant bank as we obtain:

$$
\begin{aligned}
\mathrm{E}_{t} N_{d, t+1}^{(\text {survd })} & =\mathrm{E}_{t}\left[N_{d, t+1} \mid \tilde{R}_{s, t} \in\left[\underline{R}_{s d, t}, \underline{R}_{s, t}\right]\right] \\
& =\left[R_{t}+\frac{B_{t}}{N_{d, t}}\left(\mu_{b, t}^{(\text {survd })}-R_{t}\right)-\frac{D_{t}}{N_{d, t}}\left(R_{d, t}-R_{t}\right)\right] N_{d, t},
\end{aligned}
$$

where $\mu_{b, t}^{(\text {survd })}=\mu_{s, t}^{(\text {survd })}(1+\mathrm{h})(1-\xi)+R_{t} \frac{\mathrm{h}\left(1-a_{m, t}\right)}{a_{m, t}}$ is the expected return on the loan when the merchant bank defaults.

Case 3': Deposit bank default $\left(\tilde{R}_{s, t} \leq \underline{R}_{s d, t}\right)$. The deposit bank defaults when the merchant bank defaults $\left(\tilde{R}_{s, t} \leq \underline{R}_{s, t}\right)$ and the deposit bank cannot repay all its deposits. In this case, we have that the value of the deposits that the deposit bank can repay is: $D_{t+1}^{(\text {defd })}=R_{t}\left(M_{m, t}+\right.$ $\left.M_{d, t}\right)+\tilde{R}_{s, t}(1-\xi) S_{t}$ and its capital shortfall is:

$$
C S_{t}=R_{d, t} D_{t}-D_{t+1}^{(d e f d)}
$$

\section{A.5 Public Sector}

Government spending, transfers, interest payment, and the government deposit guarantee are financed by (i) government nominal bonds sold to (merchant and deposit) banks, (ii) consumption, labor income, and capital taxes. The government faces the budget constraint:

$$
G_{t}+\operatorname{Tr}_{t}+R_{t-1} B_{g, t-1}+\Omega_{t}=\left[\tau_{c} C_{t}+\tau_{s} W_{t} L_{t}+\tau_{s} R_{k, t} \bar{K}_{t-1}\right]+B_{g, t}
$$

where real (unproductive) government purchases is set according to $G_{t}=\left(1-\frac{1}{\varepsilon_{g, t}}\right) Y_{t}$, and $\varepsilon_{g, t}$ is a government spending shock. The net cost of deposit insurance is defined as: $\Omega_{t}=$ $\left(R_{d, t} D_{t}-D_{t+1}^{(d e f d)}\right) 1_{\left\{\tilde{R}_{s, t}<\underline{R}_{s d, t}\right\}}-\Pi_{i n s, t} D_{t}$. The first term corresponds to the capital shortfall in case of a default of the deposit bank, whereas the second term is the insurance premium paid by banks to the government each period.

The monetary authority follows a generalized-Taylor rule by gradually adjusting the nominal interest rate in response to inflation and output growth:

$$
\frac{R_{t}}{R}=\left(\frac{R_{t-1}}{R}\right)^{\varphi_{r}}\left[\left(\frac{\pi_{t}}{\pi}\right)^{\varphi_{\pi}}\left(\frac{Y_{t}}{\mu_{z} Y_{t-1}}\right)^{\varphi_{y}}\right]^{\left(1-\varphi_{r}\right)} \varepsilon_{r, t},
$$

where $R$ is the steady state of the gross nominal interest rate and $\varepsilon_{r, t}$ is a monetary policy shock. The parameter $\varphi_{r}$ captures the degree of interest rate smoothing. 


\section{A.6 Market Clearing and Stochastic Processes}

Market clearing conditions on final goods market are given by

$$
\begin{aligned}
Y_{t} & =C_{t}+I_{t}+G_{t}+\mathscr{S}_{u}\left(u_{t}\right) \bar{K}_{t-1} \\
\Delta_{p, t} Y_{t} & =\varepsilon_{a, t}\left(u_{t} K_{t}\right)^{\alpha}\left(Z_{t} L_{t}\right)^{1-\alpha}-Z_{t} \Phi_{Y}=Y_{m, t},
\end{aligned}
$$

where $\Delta_{p, t}=\int_{0}^{1}\left(\frac{P_{t}(\varsigma)}{P_{t}}\right)^{-\zeta_{p}} \mathrm{~d} \varsigma$ is a measure of the price dispersion. The labor market clears as: $L_{t}=\int_{0}^{1} L_{t}(f) d f$. The short-term government bond market-clearing condition is given by $B_{g, t}=M_{m, t}+M_{d, t}$.

The total factor productivity is a non-stationary process: $Z_{t} / Z_{t-1}=\mu_{z, t} / \mu_{z}$, where $\mu_{z, t}$ is an iid shock. The stationary shock to the total factor productivity $\left(\varepsilon_{a, t}\right)$, the preference shock $\left(\varepsilon_{b, t}\right)$, the investment shock $\left(\varepsilon_{i, t}\right)$, the public expenditure shock $\left(\varepsilon_{g, t}\right)$, the price mark-up shock $\left(\varepsilon_{p, t}\right)$, and the wage mark-up shock $\left(\varepsilon_{w, t}\right)$ have an $\operatorname{AR}(1)$ dynamics:

$$
\log \left(\varepsilon_{x, t} / \varepsilon_{x}\right)=\rho_{x} \log \left(\varepsilon_{x, t-1} / \varepsilon_{x}\right)+\zeta_{x, t}
$$

with $x \in\{a, b, i, g, p, w\}$ and $\varepsilon_{x}$ the long-term value of the shock. For the monetary policy shock, we impose that $\rho_{r}=0$, so that it is an iid process. Similarly, the risk shock has an AR(1) dynamics;

$$
\log \left(\sigma_{s, t} / \sigma_{s}\right)=\rho_{\sigma} \log \left(\sigma_{s, t-1} / \sigma_{s}\right)+\zeta_{\sigma, t}
$$

In all cases, $\zeta_{x, t} \sim$ iid $N\left(0, \sigma_{x}^{2}\right)$, with $x \in\{a, b, i, g, p, w, \sigma\}$.

\section{B Equilibrium conditions}

This section reports the first-order conditions for the agents' optimizing problems and the other relationships that define the equilibrium of the model.

\section{B.1 Household Sector}

- Marginal utility of consumption:

$$
\left(1+\tau_{c}\right) \Lambda_{t}=\frac{\varepsilon_{b, t}}{C_{t}-\gamma C_{t-1}}-\beta \gamma \mathrm{E}_{t}\left(\frac{\varepsilon_{b, t+1}}{C_{t+1}-\gamma C_{t}}\right)
$$


- Consumption Euler equation:

$$
\Lambda_{t}=\beta R_{t} \mathrm{E}_{t}\left(\Lambda_{t+1} \frac{P_{t}}{P_{t+1}}\right)
$$

\section{B.2 Production Sector}

- Efficient capital:

$$
K_{t}=\omega_{t} \bar{K}_{t-1}
$$

- Capital accumulation:

$$
\bar{K}_{t+1}=(1-\delta) \bar{K}_{t}+\varepsilon_{i, t}\left(1-\mathscr{S}_{i}\left(\frac{I_{t}}{I_{t-1}}\right)\right) I_{t}
$$

- Production function:

$$
Y_{m, t}=\varepsilon_{a, t}\left(u_{t} K_{t}\right)^{\alpha}\left(Z_{t} L_{t}\right)^{1-\alpha}-Z_{t} \Phi_{Y}
$$

- Investment equation:

$$
1=Q_{t} \varepsilon_{i, t}\left[1-\mathscr{S}_{i}\left(\frac{I_{t}}{I_{t-1}}\right)-\frac{I_{t}}{I_{t-1}} \mathscr{S}_{i}^{\prime}\left(\frac{I_{t}}{I_{t-1}}\right)\right]+\beta \mathrm{E}_{t}\left[\frac{\Lambda_{t+1}}{\Lambda_{t}} Q_{t+1} \varepsilon_{i, t+1}\left(\frac{I_{t+1}}{I_{t}}\right)^{2} \mathscr{S}_{i}^{\prime}\left(\frac{I_{t+1}}{I_{t}}\right)\right]
$$

- Rate of return of firm's securities: $\tilde{R}_{s, t}(f)=\omega_{t}(f) \hat{\mu}_{s, t}$, with

$$
\hat{\mu}_{s, t}=\frac{\left(1-\tau_{k}\right)\left(r_{k, t} u_{t}-\mathscr{S}_{u}\left(u_{t}\right)\right) P_{t}+(1-\delta) Q_{t}}{Q_{t-1}}+\tau_{k} \delta
$$

- Capital utilization:

$$
r_{k, t}=\mathscr{S}_{u}^{\prime}\left(u_{t}\right)
$$

- Labor demand:

$$
\frac{W_{t}}{Z_{t} P_{t}}=(1-\alpha) \varepsilon_{a, t}\left(\frac{u_{t} K_{t}}{Z_{t} L_{t}}\right)^{\alpha} \frac{P_{m, t}}{P_{t}}
$$

- Real rate of capital renting:

$$
r_{k, t}=\mathscr{S}_{u}^{\prime}\left(u_{t}\right)=\alpha \varepsilon_{a, t} u_{t}\left(\frac{u_{t} K_{t}}{Z_{t} L_{t}}\right)^{\alpha-1} \frac{P_{m, t}}{P_{t}}
$$

- Price setting:

$$
\mathrm{E}_{t} \sum_{s=0}^{\infty}\left(\beta \theta_{p}\right)^{s} \frac{\Lambda_{t+s}}{\Lambda_{t}}\left[\Pi_{t, t+s}^{p} P_{t}^{\star}-\varepsilon_{p, t+s} P_{m, t+s}\right] Y_{t+s}=0
$$


where $\varepsilon_{p}=\frac{\zeta_{p}}{\zeta_{p}-1}$ is the steady-state price markup. We allow for exogenous variations in it, reason why it appears time-indexed.

- Aggregate price index:

$$
1=\left(1-\theta_{p}\right)\left(\frac{P_{t}^{\star}}{P_{t}}\right)^{1-\zeta_{p}}+\theta_{p}\left(\frac{\pi^{1-\gamma_{p}} \pi_{t-1}^{\gamma_{p}}}{\pi_{t}}\right)^{1-\zeta_{p}}
$$

- Wage setting:

$$
\mathrm{E}_{t} \sum_{s=0}^{\infty}\left(\beta \theta_{w}\right)^{s} \Lambda_{t+s} L_{t+s}\left[\frac{\left(1-\tau_{s}\right) W_{t+s}}{P_{t+s}} \Pi_{t, t+s}^{w}-\varepsilon_{w, t+s} \varepsilon_{b, t+s} \frac{\chi\left(L_{t+s}\right)^{v}}{\Lambda_{t+s}}\right]=0
$$

where $\varepsilon_{w}=\frac{\zeta_{w}}{\zeta_{w}-1}$ is the steady-state wage markup. We allow for exogenous variations in it, reason why it appears time-indexed.

- Aggregate wage index:

$$
\frac{W_{t}}{P_{t}}=\left[\left(1-\theta_{w}\right)\left(\frac{W_{t}^{\star}}{P_{t}}\right)^{1-\zeta_{w}}+\theta_{w}\left(\frac{\pi^{1-\gamma_{p}} \pi_{t-1}^{\gamma_{w}}}{\pi_{t}} \frac{W_{t-1}}{P_{t-1}}\right)^{1-\zeta_{w}}\right]^{\frac{1}{1-\zeta_{w}}}
$$

- Value of the long-term claim:

$$
S_{t}=Q_{t-1} \bar{K}_{t-1}
$$

\section{B.3 Banking Sector}

- Merchant bank cash:

$$
M_{m, t}=\frac{\mathrm{h}\left(1-a_{m, t}\right)}{a_{m, t}(1+\mathrm{h})} S_{t}
$$

- Deposit bank cash:

$$
M_{d, t}=\left(1-a_{d, t}\right) D_{t}
$$

- Merchant bank net worth:

$$
N_{m, t}=M_{m, t}+S_{t}-B_{t}
$$

- Capital ratio restriction:

$$
B_{t}=\frac{a_{d, t}+\vartheta \omega w_{o}\left(1-a_{d, t}\right)}{1-\vartheta\left(w_{b}+\omega w_{o}\right)} D_{t}
$$


- Deposit bank net worth:

$$
N_{d, t}=M_{d, t}+B_{t}-D_{t}
$$

- Interbank rate:

$$
R_{b, t}=R_{t}+\Pi_{b, t}
$$

- Interbank risk premium:

$$
\Pi_{b, t}=\left[R_{b, t}-\mu_{s, t}^{(d e f m)}(1+\mathrm{h})(1-\xi)-R_{t} \frac{\mathrm{h}\left(1-a_{m, t}\right)}{a_{m, t}}\right] \Phi_{s}\left(\underline{R}_{s, t}\right)
$$

with $\mu_{s, t}^{(\text {defm })}=\mathrm{E}_{t}\left[\tilde{R}_{s, t} \mid \tilde{R}_{s, t} \leq \underline{R}_{s, t}\right]$

- Deposit rate:

$$
R_{d, t}=R_{t}+\Pi_{i n s, t}
$$

- Insurance premium:

$$
\Pi_{i n s, t} D_{t}=\left[R_{d, t} D_{t}-\mu_{s, t}^{(d e f d)}(1-\xi) S_{t}-R_{t}\left(M_{m, t}+M_{d, t}\right)\right] \Phi_{s}\left(\underline{R}_{s d, t}\right)
$$

with $\mu_{s, t}^{(\text {defd })}=\mathrm{E}_{t}\left[\tilde{R}_{s, t} \mid \tilde{R}_{s, t} \leq \underline{R}_{s d, t}\right]$

- Optimal cash holding of the merchant bank:

$$
\begin{array}{r}
-\Psi\left(a_{m, t}\right) \frac{\partial N_{m, t}}{\partial a_{m, t}} \frac{1}{N_{m, t}}+\frac{\psi_{m}}{2}\left(\frac{a_{m, t}}{a_{m, t-1}}-1\right)\left[\frac{2 a_{m, t}}{a_{m, t-1}}+\left(\frac{a_{m, t}}{a_{m, t-1}}-1\right)\right] \\
=\beta \frac{\Lambda_{t+1}}{\Lambda_{t}} \psi_{m}\left(\frac{a_{m, t+1}}{a_{m, t}}-1\right)\left(\frac{a_{m, t+1}}{a_{m, t}}\right)^{2} \frac{N_{m, t+1}}{N_{m, t}}
\end{array}
$$

where $\Psi\left(a_{m, t}\right)=1-\frac{\psi_{m}}{2}\left(\frac{a_{m, t+s}}{a_{m, t+s-1}}-1\right)^{2} a_{m, t+s}$

- Optimal cash holding of the deposit bank:

$$
\begin{array}{r}
1+\frac{\psi_{d}}{2}\left(\frac{a_{d, t}}{a_{d, t-1}}-1\right)\left[\frac{2 a_{d, t}}{a_{d, t-1}}+\left(\frac{a_{d, t}}{a_{d, t-1}}-1\right)\right] \\
=\beta \frac{\Lambda_{t+1}}{\Lambda_{t}} \psi_{d}\left(\frac{a_{d, t+1}}{a_{d, t}}-1\right)\left(\frac{a_{d, t+1}}{a_{d, t}}\right)^{2} \frac{D_{t+1}}{D_{t}}
\end{array}
$$


- Thresholds:

$$
\begin{aligned}
\bar{R}_{s, t} & =\frac{1}{1+\mathrm{h}}\left[R_{b, t}-R_{t} \frac{\mathrm{h}\left(1-a_{m, t}\right)}{a_{m, t}}\right] \\
\underline{R}_{s, t} & =\frac{\bar{R}_{s, t}}{1-\phi} \\
\underline{R}_{s d, t} & =\frac{1}{(1+\mathrm{h})(1-\xi)}\left[R_{d, t} \frac{D_{t}}{B_{t}}-R_{t}\left(1-a_{m, t}\right) \frac{N_{d, t}}{B_{t}}-R_{t} \frac{\mathrm{h}\left(1-a_{m, t}\right)}{a_{m, t}}\right]
\end{aligned}
$$

\section{B.4 Intraperiod dynamic of bank quantities}

- Cash of the merchant bank:

$$
\tilde{M}_{m, t}=\left[R_{t} M_{m, t}-\left(R_{b, t}-1\right) B_{t}\right]\left(1-\Phi_{s}\left(\bar{R}_{s, t}\right)\right)
$$

- Cash of the deposit bank:

$$
\tilde{M}_{d, t}=\left[R_{t} M_{d, t}+\left(R_{b, t}-1\right) B_{t}\right]\left(1-\Phi_{s}\left(\underline{R}_{s, t}\right)\right)+\left[R_{t}\left(M_{m, t}+M_{d, t}\right)+\mu_{s, t}^{(d e f m)}(1-\xi) S_{t}\right] \Phi_{s}\left(\underline{R}_{s, t}\right)
$$

- Long-term claim:

$$
\begin{aligned}
& \tilde{S}_{t}=\mu_{s, t}^{(\text {good })} S_{t}\left(1-\Phi_{s}\left(\bar{R}_{s, t}\right)\right)+\psi\left[-R_{b, t} B_{t}+R_{t} M_{m, t}+\mu_{s, t}^{(\text {fire })}(1-\phi) S_{t}\right]\left(\Phi_{s}\left(\bar{R}_{s, t}\right)-\Phi_{s}\left(\underline{R}_{s, t}\right)\right) \\
& \text { with } \mu_{s, t}^{(\text {good })}=\mathrm{E}_{t}\left[\tilde{R}_{s, t} \mid \tilde{R}_{s, t}>\bar{R}_{s, t}\right] \text { and } \mu_{s, t}^{(\text {fire })}=\mathrm{E}_{t}\left[\tilde{R}_{s, t} \mid \tilde{R}_{s, t} \in\left[\underline{R}_{s, t} ; \bar{R}_{s, t}\right]\right]
\end{aligned}
$$

- Interbank debt:

$$
\tilde{B}_{t}=B_{t}\left(1-\Phi_{s}\left(\bar{R}_{s, t}\right)\right)+\frac{\psi}{1+\mathrm{h}}\left[-R_{b, t} B_{t}+R_{t} M_{m, t}+\mu_{s, t}^{(\text {fire })}(1-\phi) S_{t}\right]\left(\Phi_{s}\left(\bar{R}_{s, t}\right)-\Phi_{s}\left(\underline{R}_{s, t}\right)\right)
$$

- Deposits:

$$
\tilde{D}_{t}=R_{d, t} D_{t}\left(1-\Phi_{s}\left(\underline{R}_{s d, t}\right)\right)+\left[R_{t}\left(M_{m, t}+M_{d, t}\right)+\mu_{s, t}^{(d e f d)}(1-\xi) S_{t}\right] \Phi_{s}\left(\underline{R}_{s d, t}\right)
$$

\section{B.5 Public Sector}

- Government spending:

$$
G_{t}=\left(1-\frac{1}{\varepsilon_{g, t}}\right) Y_{t}
$$


- Monetary policy rule:

$$
\frac{R_{t}}{R}=\left(\frac{R_{t-1}}{R}\right)^{\varphi_{r}}\left[\left(\frac{\pi_{t}}{\pi}\right)^{\varphi_{\pi}}\left(\frac{Y_{t}}{\mu_{z} Y_{t-1}}\right)^{\varphi_{y}}\right]^{\left(1-\varphi_{r}\right)} \varepsilon_{r, t}
$$

- Macroprudential policy rule:

$$
\frac{\vartheta_{t}}{\vartheta}=\left(\frac{Y_{t}}{\mu_{z} Y_{t-1}}\right)^{\beta_{\Delta y}}\left(\frac{S_{t}}{\mu_{z} S_{t-1}}\right)^{\beta_{\Delta S}}\left(\frac{S E L_{t}}{Y_{t}}\right)^{\beta_{S E L}},
$$

where

$$
S E L_{t}=\left[R_{d, t} D_{t}-\mu_{s, t}^{(d e f d \mid c r i s i s)}(1-\xi) S_{t}-R_{t}\left(M_{m, t}+M_{d, t}\right)\right] \Pi_{t}^{(d e f d \mid c r i s i s)}
$$

where $\mu_{s, t}^{(\text {defd } \mid \text { crisis })}=\mathrm{E}_{t}\left[\tilde{R}_{s, t} \mid \tilde{R}_{s, t} \leq \underline{R}_{s d, t}\right.$; crisis $]$ and $\Pi_{t}^{(\text {defd } \mid \text { crisis })}=\operatorname{Pr}\left[\tilde{R}_{s, t} \leq \underline{R}_{s d, t} \mid\right.$ crisis $]$.

\section{B.6 Market Clearing}

- Resource constraint:

$$
\begin{aligned}
Y_{t} & =C_{t}+I_{t}+G_{t}+\mathscr{S}_{u}\left(u_{t}\right) \bar{K}_{t-1} \\
\Delta_{p, t} Y_{t} & =Y_{m, t}=\varepsilon_{a, t}\left(u_{t} K_{t}\right)^{\alpha}\left(Z_{t} L_{t}\right)^{1-\alpha}-Z_{t} \Phi_{Y}
\end{aligned}
$$

- Short-term government debt:

$$
B_{g, t}=M_{m, t}+M_{d, t}
$$

\section{Stationary equilibrium}

To find the steady-state, we express the model in stationary form. Thus, for the non-stationary variables, let lower-case denote their value relative to the technology process $Z_{t}: x_{t} \equiv X_{t} / Z_{t}$. We note that the marginal utility of consumption $\Lambda_{t}$ will shrink as the economy grows, such that $\lambda_{t} \equiv \Lambda_{t} Z_{t}$, and we express the wage in real terms $w_{t} \equiv W_{t} /\left(Z_{t} P_{t}\right)$. Also, we denote the real rental rate of capital and real marginal cost by

$$
r_{k, t} \equiv R_{k, t} / P_{t} \quad \text { and } \quad p_{m, t} \equiv P_{m, t} / P_{t}
$$


and the optimal relative price as

$$
p_{t}^{\star} \equiv P_{t}^{\star} / P_{t}
$$

Then we can rewrite the model in terms of stationary variables as follows.

\section{C.1 Household Sector}

- Marginal utility of consumption:

$$
\left(1+\tau_{c}\right) \lambda_{t}=\frac{\varepsilon_{b, t} \mu_{z, t}}{\mu_{z, t} c_{t}-\gamma c_{t-1}}-\beta \gamma \mathrm{E}_{t}\left(\frac{\varepsilon_{b, t+1}}{\mu_{z, t+1} c_{t+1}-\gamma c_{t}}\right)
$$

- Consumption Euler equation:

$$
\lambda_{t}=\beta R_{t} \mathrm{E}_{t}\left(\frac{\lambda_{t+1}}{\mu_{z, t+1} \pi_{t+1}}\right)
$$

\section{C.2 Production Sector}

- Efficient capital:

$$
k_{t}=\frac{\omega_{t} \bar{k}_{t-1}}{\mu_{z, t}}
$$

- Capital accumulation:

$$
\bar{k}_{t+1}=(1-\delta) \frac{\bar{k}_{t}}{\mu_{z, t}}+\varepsilon_{i, t}\left(1-\mathscr{S}_{i}\left(\frac{i_{t}}{i_{t-1}} \mu_{z, t}\right)\right) i_{t}
$$

- Production function:

$$
y_{m, t}=\varepsilon_{a, t}\left(u_{t} k_{t}\right)^{\alpha} L_{t}^{1-\alpha}-\Phi_{Y}
$$

- Investment equation:

$$
\begin{aligned}
1= & q_{t} \varepsilon_{i, t}\left[1-\mathscr{S}_{i}\left(\frac{i_{t}}{i_{t-1}} \mu_{z, t}\right)-\frac{i_{t}}{i_{t-1}} \mu_{z, t} \mathscr{S}_{i}^{\prime}\left(\frac{i_{t}}{i_{t-1}} \mu_{z, t}\right)\right] \\
& +\beta \mathrm{E}_{t}\left[\frac{\lambda_{t+1}}{\lambda_{t} \mu_{z, t+1}} q_{t+1} \varepsilon_{i, t+1}\left(\frac{i_{t+1}}{i_{t}} \mu_{z, t+1}\right)^{2} \mathscr{S}_{i}^{\prime}\left(\frac{i_{t+1}}{i_{t}} \mu_{z, t+1}\right)\right]
\end{aligned}
$$

- Rate of return of firm's securities: $\tilde{R}_{s, t}(f)=\omega_{t}(f) \hat{\mu}_{s, t}$, with

$$
\hat{\mu}_{s, t}=\frac{\left(1-\tau_{k}\right)\left(r_{k, t} u_{t}-\mathscr{S}_{u}\left(u_{t}\right)\right)+(1-\delta) q_{t} \pi_{t}}{q_{t-1}}+\tau_{k} \delta
$$


- Capital utilization:

$$
r_{k, t}=\mathscr{S}_{u}^{\prime}\left(u_{t}\right)
$$

- Labor demand:

$$
w_{t}=(1-\alpha) \varepsilon_{a, t}\left(\frac{u_{t} k_{t}}{L_{t}}\right)^{\alpha} p_{m, t}
$$

- Real rate of capital renting:

$$
r_{k, t}=\alpha \varepsilon_{a, t} \frac{u_{t}}{\mu_{z, t}}\left(\frac{u_{t} k_{t}}{L_{t}}\right)^{\alpha-1} p_{m, t}
$$

- Price setting:

$$
\mathrm{E}_{t} \sum_{s=0}^{\infty}\left(\beta \theta_{p}\right)^{s} \frac{\lambda_{t+s}}{\lambda_{t}}\left[\Pi_{t, t+s}^{p} p_{t}^{\star} \frac{P_{t}}{P_{t+s}}-\varepsilon_{p, t+s} p_{m, t+s}\right] y_{t+s}=0
$$

- Aggregate price index:

$$
1=\left(1-\theta_{p}\right)\left(p_{t}^{\star}\right)^{1-\zeta_{p}}+\theta_{p}\left(\frac{\tilde{\pi}_{t}}{\pi_{t} \mu_{z, t}}\right)^{1-\zeta_{p}}
$$

where $\tilde{\pi}_{t}=\pi^{1-\gamma_{p}} \pi_{t-1}^{\gamma_{p}}$

- Wage setting:

$$
\mathrm{E}_{t} \sum_{s=0}^{\infty}\left(\beta \theta_{w}\right)^{s} \lambda_{t+s} L_{t+s}\left[\left(1-\tau_{s}\right) w_{t+s} \frac{P_{t}}{P_{t+s}} \frac{Z_{t}}{Z_{t+s}} \prod_{t, t+s}^{w}-\varepsilon_{w, t+s} \varepsilon_{b, t+s} \frac{\chi\left(L_{t+s}\right)^{v}}{\lambda_{t+s}}\right]=0
$$

- Aggregate wage index:

$$
1=\left(1-\theta_{w}\right)\left(\frac{w_{t}^{\star}}{w_{t}}\right)^{1-\zeta_{w}}+\theta_{w}\left(\frac{\tilde{\pi}_{w, t}}{\pi_{w, t}}\right)^{1-\zeta_{w}}
$$

where $\pi_{w, t}=\frac{w_{t}}{w_{t-1}} \pi_{t} \mu_{z, t}$ and $\tilde{\pi}_{w, t}=\left(\pi \mu_{z}\right)^{1-\gamma_{w}}\left(\pi_{t-1} \mu_{z, t}\right)^{\gamma_{w}}$

\section{C.3 Banking Sector}

- Merchant bank cash:

$$
m_{m, t}=\frac{\mathrm{h}\left(1-a_{m, t}\right)}{a_{m, t}(1+\mathrm{h})} s_{t}
$$


- Deposit bank cash:

$$
m_{d, t}=\left(1-a_{d, t}\right) d_{t}
$$

- Merchant bank net worth:

$$
n_{m, t}=m_{m, t}+s_{t}-b_{t}
$$

- Capital ratio restriction:

$$
b_{t}=\frac{a_{d, t}+\vartheta \omega w_{o}\left(1-a_{d, t}\right)}{1-\vartheta\left(w_{b}+\omega w_{o}\right)} d_{t}
$$

- Deposit bank net worth:

$$
n_{d, t}=m_{d, t}+b_{t}-d_{t}
$$

- Interbank rate:

$$
R_{b, t}=R_{t}+\Pi_{b, t}
$$

- Interbank risk premium:

$$
\Pi_{b, t}=\left[R_{b, t}-\mu_{s, t}^{(d e f m)}(1+\mathrm{h})(1-\xi)-R_{t} \frac{\mathrm{h}\left(1-a_{m, t}\right)}{a_{m, t}}\right] \Phi_{s}\left(\underline{R}_{s, t}\right)
$$

with $\mu_{s, t}^{(\text {defm })}=\mathrm{E}_{t}\left[\tilde{R}_{s, t} \mid \tilde{R}_{s, t} \leq \underline{R}_{s, t}\right]$

- Deposit rate:

$$
R_{d, t}=R_{t}+\Pi_{i n s, t}
$$

- Insurance premium:

$$
\Pi_{i n s, t} d_{t}=\left[R_{d, t} d_{t}-\mu_{s, t}^{(d e f d)}(1-\xi) s_{t}-R_{t}\left(m_{m, t}+m_{d, t}\right)\right] \Phi_{s}\left(\underline{R}_{s d, t}\right)
$$

with $\mu_{s, t}^{(\text {defd })}=\mathrm{E}_{t}\left[\tilde{R}_{s, t} \mid \tilde{R}_{s, t} \leq \underline{R}_{s d, t}\right]$

- Optimal cash holding of the merchant bank:

$$
\begin{aligned}
-\Psi\left(a_{m, t}\right) \frac{\partial n_{m, t}}{\partial a_{m, t}} \frac{1}{N_{m, t}}+ & \frac{\psi_{m}}{2}\left(\frac{a_{m, t}}{a_{m, t-1}}-1\right)\left[\frac{2 a_{m, t}}{a_{m, t-1}}+\left(\frac{a_{m, t}}{a_{m, t-1}}-1\right)\right] \\
& =\beta \frac{\lambda_{t+1}}{\varepsilon_{z, t+1} \lambda_{t}} \psi_{m}\left(\frac{a_{m, t+1}}{a_{m, t}}-1\right)\left(\frac{a_{m, t+1}}{a_{m, t}}\right)^{2} \frac{n_{m, t+1}}{n_{m, t}}
\end{aligned}
$$

where $\Psi\left(a_{m, t}\right)=1-\frac{\psi_{m}}{2}\left(\frac{a_{m, t}}{a_{m, t-1}}-1\right)^{2} a_{m, t}$ 
- Optimal cash holding of the deposit bank:

$$
\begin{array}{r}
1+\frac{\psi_{d}}{2}\left(\frac{a_{d, t}}{a_{d, t-1}}-1\right)\left[\frac{2 a_{d, t}}{a_{d, t-1}}+\left(\frac{a_{d, t}}{a_{d, t-1}}-1\right)\right] \\
=\beta \frac{\lambda_{t+1}}{\varepsilon_{z, t+1} \lambda_{t}} \psi_{d}\left(\frac{a_{d, t+1}}{a_{d, t}}-1\right)\left(\frac{a_{d, t+1}}{a_{d, t}}\right)^{2} \frac{d_{t+1}}{d_{t}}
\end{array}
$$

\section{C.4 Intraperiod dynamic of bank quantities}

- Cash of the merchant bank:

$$
\tilde{m}_{m, t}=\left[R_{t} m_{m, t}-\left(R_{b, t}-1\right) b_{t}\right]\left(1-\Phi_{s}\left(\bar{R}_{s, t}\right)\right)
$$

- Cash of the deposit bank:

$$
\tilde{m}_{d, t}=\left[R_{t} m_{d, t}+\left(R_{b, t}-1\right) b_{t}\right]\left(1-\Phi_{s}\left(\underline{R}_{s, t}\right)\right)+\left[R_{t}\left(m_{m, t}+m_{d, t}\right)+\mu_{s, t}^{(d e f m)}(1-\xi) s_{t}\right] \Phi_{s}\left(\underline{R}_{s, t}\right)
$$

- Long-term claim:

$$
\begin{aligned}
& \tilde{s}_{t}=\mu_{s, t}^{(\text {good })} s_{t}\left(1-\Phi_{s}\left(\bar{R}_{s, t}\right)\right)+\psi\left[-R_{b, t} b_{t}+R_{t} m_{m, t}+\mu_{s, t}^{(\text {fire })}(1-\phi) s_{t}\right]\left(\Phi_{s}\left(\bar{R}_{s, t}\right)-\Phi_{s}\left(\underline{R}_{s, t}\right)\right) \\
& \text { with } \mu_{s, t}^{(\text {good })}=\mathrm{E}_{t}\left[\tilde{R}_{s, t} \mid \tilde{R}_{s, t}>\bar{R}_{s, t}\right] \text { and } \mu_{s, t}^{(\text {fire })}=\mathrm{E}_{t}\left[\tilde{R}_{s, t} \mid \tilde{R}_{s, t} \in\left[\underline{R}_{s, t} ; \bar{R}_{s, t}\right]\right]
\end{aligned}
$$

- Interbank debt:

$$
\tilde{b}_{t}=b_{t}\left(1-\Phi_{s}\left(\bar{R}_{s, t}\right)\right)+\frac{\psi}{1+\mathrm{h}}\left[-R_{b, t} b_{t}+R_{t} m_{m, t}+\mu_{s, t}^{(f i r e)}(1-\phi) S_{t}\right]\left(\Phi_{s}\left(\bar{R}_{s, t}\right)-\Phi_{s}\left(\underline{R}_{s, t}\right)\right)
$$

- Deposits:

$$
\tilde{d}_{t}=R_{d, t} d_{t}\left(1-\Phi_{s}\left(\underline{R}_{s d, t}\right)\right)+\left[R_{t}\left(m_{m, t}+m_{d, t}\right)+\mu_{s, t}^{(d e f d)}(1-\xi) s_{t}\right] \Phi_{s}\left(\underline{R}_{s d, t}\right)
$$

\section{C.5 Public Sector}

- Government spending:

$$
g_{t}=\left(1-\frac{1}{\varepsilon_{g, t}}\right) y_{t},
$$

- Monetary policy rule:

$$
\frac{R_{t}}{R}=\left(\frac{R_{t-1}}{R}\right)^{\varphi_{r}}\left[\left(\frac{\pi_{t}}{\pi}\right)^{\varphi_{\pi}}\left(\frac{y_{t}}{y_{t-1}} \frac{\mu_{z, t}}{\mu_{z}}\right)^{\varphi_{y}}\right]^{\left(1-\varphi_{r}\right)} \varepsilon_{r, t}
$$


- Macroprudential policy rule:

$$
\frac{\vartheta_{t}}{\vartheta}=\left(\frac{y_{t}}{y_{t-1}} \frac{\mu_{z, t}}{\mu_{z}}\right)^{\beta_{\Delta y}}\left(\frac{s_{t}}{s_{t-1}} \frac{\mu_{z, t}}{\mu_{z}}\right)^{\beta_{\Delta S}}\left(\frac{S E L_{t}}{Y_{t}}\right)^{\beta_{S E L}}
$$

where

$$
S E L_{t}=\left[R_{d, t} d_{t}-\mu_{s, t}^{(d e f d \mid c r i s i s)}(1-\xi) s_{t}-R_{t}\left(m_{m, t}+m_{d, t}\right)\right] \Pi_{t}^{(d e f d \mid c r i s i s)}
$$

\section{C.6 Market Clearing}

- Resource constraint:

$$
\begin{aligned}
y_{t} & =c_{t}+i_{t}+g_{t}+\mathscr{S}_{u}\left(u_{t}\right) \bar{k}_{t} / \mu_{z, t} \\
\Delta_{p, t} y_{t} & =y_{m, t}
\end{aligned}
$$

- Short-term government debt:

$$
b_{g, t}=m_{m, t}+m_{d, t}
$$

